\title{
Hydrometeorological effects of historical land-conversion in an ecosystem-atmosphere model of Northern South America
}

\author{
R. G. Knox ${ }^{1, *}$, M. Longo ${ }^{2, * *}$, A. L. S. Swann ${ }^{3}$, K. Zhang ${ }^{2, * *}$, N. M. Levine ${ }^{2, * * *}$, P. R. Moorcroft ${ }^{2}$, and R. L. Bras ${ }^{4}$ \\ ${ }^{1}$ Massachusetts Institute of Technology, Cambridge, Massachusetts, USA \\ ${ }^{2}$ Harvard University, Cambridge, Massachusetts, USA \\ ${ }^{3}$ University of Washington, Seattle, Washington, USA \\ ${ }^{4}$ Georgia Institute of Technology, Atlanta, Georgia, USA \\ * now at: Lawrence Berkeley National Laboratory, Berkeley, California, USA \\ ** now at: EMBRAPA Satellite Monitoring, Campinas, São Paulo, Brazil \\ *** now at: Cooperative Institute for Mesoscale Meteorological Studies, University of Oklahoma, Oklahoma, USA \\ **** now at: University of Southern California, Los Angeles, California, USA
}

Correspondence to: R. G. Knox (rgknox@lbl.gov)

Received: 22 October 2013 - Published in Hydrol. Earth Syst. Sci. Discuss.: 13 December 2013

Revised: 3 November 2014 - Accepted: 23 November 2014 - Published: 15 January 2015

\begin{abstract}
This work investigates how the integrated land use of northern South America has affected the present day regional patterns of hydrology. A model of the terrestrial ecosystems (ecosystem demography model 2: ED2) is combined with an atmospheric model (Brazilian Regional Atmospheric Modeling System: BRAMS). Two realizations of the structure and composition of terrestrial vegetation are used as the sole differences in boundary conditions that drive two simulations. One realization captures the present day vegetation condition that includes deforestation and land conversion, the other is an estimate of the potential structure and composition of the region's vegetation without human influence. Model output is assessed for differences in resulting hydrometeorology.

The simulations suggest that the history of land conversion in northern South America is not associated with a significant precipitation bias in the northern part of the continent, but has shown evidence of a negative bias in mean regional evapotranspiration and a positive bias in mean regional runoff. Also, negative anomalies in evaporation rates showed pattern similarity with areas where deforestation has occurred. In the central eastern Amazon there was an area where deforestation and abandonment had lead to an overall reduction of above-ground biomass, but this was accompanied by a shift
\end{abstract}

in forest composition towards early successional functional types and grid-average-patterned increases in annual transpiration.

Anomalies in annual precipitation showed mixed evidence of consistent patterning. Two focus areas were identified where more consistent precipitation anomalies formed, one in the Brazilian state of Pará where a dipole pattern formed, and one in the Bolivian Gran Chaco, where a negative anomaly was identified. These locations were scrutinized to understand the basis of their anomalous hydrometeorologic response. In both cases, deforestation led to increased total surface albedo, driving decreases in net radiation, boundary layer moist static energy and ultimately decreased convective precipitation. In the case of the Gran Chaco, decreased precipitation was also a result of decreased advective moisture transport, indicating that differences in local hydrometeorology may manifest via teleconnections with the greater region. 


\section{Introduction}

It has been held that massive and widespread Amazonian deforestation would lead to regional reductions in precipitation, evaporation, and moisture convergence, with slight increases in surface temperature (Henderson-Sellers et al., 1993; Nobre et al., 1991; Lean and Warrilow, 1989; Dickinson and Henderson-Sellers, 1988). The Amazon Basin and its forest ecosystems are also an important component of the global circulation of energy (Gedney and Valdes, 2000), where changes (complete deforestation in either Amazonia or all tropical broadleaf forests) are thought to teleconnect beyond the continent (Avissar and Werth, 2005; Snyder, 2010). The literature documenting Amazonian land conversion and the surrounding areas is significant, the reader is referred to a small selection of non-exhaustive references for some background (Cardille and Foley, 2003; Skole and Tucker, 1993; INPE, 2003; Geist and Lambin, 2002; Laurance et al., 2001; Nepstad et al., 2001; Soares-Filho et al., 2006). The work presented here is motivated by a need to better understand how the history of land conversion has influenced the hydrology of the region. As will be outlined further, the mechanistic relationships between land conversion and hydrometeorological response is complex and has benefited from study with newer generations of land-atmosphere models with increased granularity and increased complexity in representing physical process.

There are several direct hydrologic mechanisms that connect changes in tropical forest structure (i.e., deforested versus intact canopies) to the regional climate system. Leaves, stems, and bare earth have variable light-scattering properties, such that intact forest canopies composed of dark vegetation typically have lower shortwave radiation albedo than areas with exposed soil (Chapin et al., 2002). This directly impacts the surface energy balance via net radiation. Forest canopies have a complex relationship with the surface moisture balance and mediate the transport of water in numerous ways. Model studies have shown that the representation of canopy interception can substantially impact the partitioning of evapotranspiration and surface runoff (Pitman et al., 1990; Wang et al., 2007; Crockford and Richardson, 2000). Some studies have found that forest canopies increase the interception of precipitation (Asdak et al., 1998; Dietz et al., 2006), and further that crown structure influences turbulent transport and evaporation of wet leaves (Dietz et al., 2006). Yet some have indicated that canopy interception increased in degraded forests (Chappell et al., 2001). Pastures and converted agricultural systems are generally associated with soil degradation such as decreased infiltration rates, nutrient loss and increased surface runoff, subject to variability and factors such as the soil texture and the existence of perennial under-story vegetation (Benegas et al., 2014). Practices such as grazing and agriculture promote soil compaction and decreased infiltration (Martinez and Zinck, 2004; Lal, 1996), and intense fires used for clearing lands may reduce soil or- ganic matter that may favor infiltration (Kennard and Gholz, 2001). Forests with deep rooted trees draw from deeper soil moisture pools, which have different periodicity in available water and therefore alter the timing of latent heat flux via transpiration compared to grasslands (Kleidon and Heimann, 2000; Nepstad et al., 1994). Canopy structure also influences the turbulent exchange of heat, moisture and momentum with the atmosphere (Raupach et al., 1996).

The higher surface temperatures associated with widespread deforestation, as reported with the first generations of general circulation models and beyond, (Henderson-Sellers et al., 1993; Nobre et al., 1991; Lean and Warrilow, 1989; Dickinson and Henderson-Sellers, 1988) are thought to be the result of losses in evaporative cooling associated with cleared vegetation. The decrease in evaporative cooling is also thought to drive reduced precipitation, and subsequently reduces the heat released to the atmosphere through condensation (Eltahir and Bras, 1993). This has the potential to outcompete the effect of increased surface albedo of deforested lands (Eltahir, 1996), which suppresses net radiation thereby promoting surface cooling and divergence (Eltahir and Bras, 1993; Lean and Warrilow, 1989). Positive surface temperature anomalies induce convergent circulations coincident with a decrease in surface pressure. Decreased precipitation heating anomalies reduce the tendency towards convergence.

In the southwestern Amazonian dry season, statistical connections have been made between pastures and higher incidents of shallow cumulus clouds, compared to intact forests where shallow clouds are less frequent yet deep precipitating convective events are more frequent (Wang et al., 2009). The higher rate of deep precipitating convection over forests was associated with larger values of convective available potential energy (CAPE) (Williams and Renno, 1993), which in this case was driven by increased humidity and moisture flux from intact forest canopies. The increased frequency of shallow convection was attributed to more vigorous mesoscale circulations associated with deforestation induced land-surface heterogeneity (Wang et al., 2000; Souza et al., 2000).

Regional land-atmosphere simulations that can parameterize convective clouds indicate that structured landconversion scenarios elicit shifts in mean basin precipitation, albeit less so than traditional coarse scale general circulation model studies (Silva et al., 2008). Coherent land surface patterns may strengthen convergence zones on the surface, creating vertical wind triggers to thunderstorms. For instance, Avissar and Werth (2005) determined that coherent land surface patterns transfer heat, moisture and wave energy to the higher latitudes through thunderstorm activity. Moreover, mesoscale simulations are found to capture key cloud feedback processes which fundamentally alter the atmospheric response to land-surface heterogeneities (Medvigy et al., 2011). The mesoscale simulation's ability to represent land-use scenarios at finer resolutions can impact spa- 
tial patterning of rainfall. For example, western propagating squall lines from the Atlantic are thought to dissipate over regions of wide-spread deforestation (Silva et al., 2008; d'Almeida et al., 2007). Evidence has also shown that convection can be driven by localized convergent air circulations triggered by land-surface heterogeneities, and that the likelihood and quality of resulting events are both dependent on the scale of heterogeneity and the position relative to disturbed and intact landscapes (Pielke, 2001; Dalu et al., 1996; Baldi et al., 2008; Anthes, 1984; Knox et al., 2011; Wang et al., 2009).

Regional scale-coupled land-atmosphere models can capture feed-backs resulting from land conversion at the scale of tens of kilometers and lower, particularly through improved resolution and the parameterization of atmospheric physics (such as convection and radiation scattering). At the land-surface, there is variability in canopy structure at the gap (size of a single large tree crown) scale and below. Processes that occur at these scales may be important to predicting ecosystem response and land-atmosphere exchange, as discussed above. Physics-based land surface models have non-linear representations of hydrologic and thermodynamic processes; therefore, using average canopy structure (such as in the "big-leaf" approach) to represent processes uniformly may provide different results compared to explicitly capturing these processes with sub-canopy and gap-scale structure.

This research uses the Brazilian Regional Atmospheric Modeling System (BRAMS, a variant of the Regional Atmospheric Modeling System (RAMS), Cotton et al., 2003) coupled with the ecosystem demography model 2 (ED2 or EDM2, Moorcroft et al., 2001; Medvigy et al., 2009), to explore the sensitivity of hydrologic climate of northern South America in response to present day land conversion. This modeling system can explicitly represent the processes of energy and mass transfer in the canopy and soil system, with sub-grid variability along ecosystem age-structured and vegetation size-structured axes. An experiment is conducted by comparing simulations that singularly differ in their representation of regional vegetation cover, one which captures the present day vegetation condition that includes deforestation and land-conversion, the other being an estimate of the potential structure and composition of the region's vegetation without human influence. Section 2 of this manuscript will detail experiment design of the coupled model experiment. The model system and experiment design is verified by comparison of model output with observations, see Appendices $\mathrm{B}-\mathrm{F}$.

In Sect. 3 we evaluate the hydrometeorological response to the changes in land-use history in a regional context. In Sect. 4 we evaluate the processes underlying the observed changes in hydrometeorology in two focus areas. A discussion and conclusion of the results follows.

\section{Experiment design}

The main task of this experiment is to conduct two regional simulations of the South American biosphere and atmosphere. The defining difference between the two simulations is how the land-surface model (ED2) represents the structure (the distribution of plant sizes) and composition (the distribution of plant types) of the region's terrestrial ecosystems, as a consequence of two different disturbance regimes. In one simulation, the vegetation reflects a structure and composition that has no effects of human land use, henceforth referred to as a potential vegetation (PV) condition. In the other simulation, the model will incorporate an estimate of modern (e.g., 2008) human land use, henceforth referred to as an actual vegetation (AV) condition. The procedure is broken down into steps and elaborated upon.

\subsection{Description of the vegetation model - ED2}

The ecosystem demography model 2 predicts the changes in the terrestrial vegetation structure, as modulated by the physically based conservation of water, carbon and enthalpy. Its central design philosophy assumes that the stochastic representation of plant communities integrated over a large sample can be portrayed deterministically as land fractions and plant groups, with explicit size (of the plants) and age (time since a patch of land housing the plants has experienced major disturbance) structure. By discretely representing the distribution of plant sizes and types, it can estimate vertical canopy structure, which directly impacts radiation scattering (throughfall interception), and in-canopy transport of scalars. By discretely representing variable disturbance history, the model can also explicitly simulate energy balance over a wide array of canopy types (closed canopies, recovering forests, grasslands, etc.) that exist within the footprint of driving meteorological data. In this experiment, the ED2 model resolves five different relevant tropical plant functional types (PFT): C4 grasses, early successional tropical evergreens, mid-successional tropical evergreens, late successional tropical evergreens and tropical C2 grasses. In the ED2 system, PFTs are used as sets of attributes that can be applied to numerous explicitly resolved plant groups of different size and in different parts of the disturbance strata.

\subsection{Generation of surface boundary conditions}

The creation of the initial vegetation conditions used a "spinup" process. The spin-up process is an off-line dynamic ED2 simulation, where the driving atmospheric information comes from a pre-compiled forcing data set. The vegetation is initialized with an equal assortment of newly recruited (saplings) plant types. The off-line model is integrated over several centuries by sampling from the climate data set as the vegetation reaches an equilibrium. We identify equilibrium when the total biomass of each plant func- 
Table 1. Simulation constraints describing the spin-up process creating the initial boundary conditions.

\begin{tabular}{|c|c|}
\hline Specification & Value \\
\hline Climate data & modified DS314* \\
\hline Soil data & Quesada et al. (2011) + IGBP-DIS \\
\hline Plant types & $\begin{array}{l}\text { late succession tropical evergreens } \\
\text { mid succession tropical evergreens } \\
\text { early succession tropical evergreens } \\
\text { subtropical grasses } \\
\text { C4 grasses }\end{array}$ \\
\hline Simulation period & 508 years \\
\hline Spatial resolution & gridded $1^{\circ}$ \\
\hline Bounding domain & $30^{\circ} \mathrm{S}-15^{\circ} \mathrm{N}, 85^{\circ} \mathrm{W}-30^{\circ} \mathrm{W}$ \\
\hline $\begin{array}{l}\text { Tree allometry } \\
\text { (DBH,height) } \\
\text { (crown properties) }\end{array}$ & $\begin{array}{l}\text { Chave et al. (2001), Baker et al. (2004b) } \\
\text { Poorter et al. (2006), Dietze et al. (2008) }\end{array}$ \\
\hline Turbulent transport & $\begin{array}{l}\text { Beljaars and Holtslag (1991) atmospheric boundary } \\
\text { Massman (1997) within canopy }\end{array}$ \\
\hline $\begin{array}{l}\text { Photosynthesis } \\
\& \text { leaf conductance }\end{array}$ & $\begin{array}{l}\text { Collatz et al. (1991) } \\
\text { Collatz et al. (1992) } \\
\text { Leuning (1995) }\end{array}$ \\
\hline Canopy radiation scattering & Zhao and Qualls $(2005,2006)$ \\
\hline Soil hydrology & $\begin{array}{l}\text { Walko et al. (2000), Tremback and Kessler (1985) } \\
\text { Medvigy et al. (2009) }\end{array}$ \\
\hline
\end{tabular}

* Modified DS314 data is derived from Sheffield et al. (2006), precipitation down-scaling and radiation interpolation is applied, see footnote for data availability.

tional type in a grid-cell does not change more than $0.5 \%$ over a period of 40 years. If equilibrium within this threshold was not achieved, the spin-up was allowed to continue to 508 years before stopping. For reference, ED2 simulations in old-growth central Amazonian forests take roughly 250 years to reach equilibrium biomass. The ED2 vegetation structure and composition at the end of the multi-century simulation was saved as the potential vegetation (PV) initial condition.

A summary of the simulation conditions in the spin-up is covered in Table 1. The model soil textures were derived from a combination of databases. Within the Amazon Basin, soil data were retrieved from Quesada et al. (2011); outside the basin soil data were retrieved from a combination of RADAMBRASIL and IGBP-DIS (Scholes et al., 1995; Rossato, 2001). The climate data used to drive the spin-up process was derived from the UCAR DS314 product (Sheffield et al., 2006) ${ }^{1}$. The DS314 is based on the National

\footnotetext{
${ }^{1}$ Original data sets used in the DS314 are from the Research Data Archive (RDA) which is maintained by the Computational and Information Systems Laboratory (CISL) at the National Center for Atmospheric Research (NCAR). The original Sheffield/DS314 data are available from the RDA (http://dss.ucar.edu) in data set number ds314.0.
}

Center for Environmental Prediction's Reanalysis Product (NCEP) and maintains the same global and temporal coverage period but has bias corrections and increased resolution based on the assimilation of composite data sets. The DS314 surface precipitation record was further processed such that grid cell average precipitation was downscaled to reflect the point-scale statistical qualities of local rain gauges. This technique used methods of Lammering and Dwyer (2000), and is explained in more detail in Knox (2012). The native NCEP reanalysis and European Center for Medium Range Weather Forecasting (ECMWF) 40 year Reanalysis (ERA40) were also tested as driver data sets. The downscaled DS314 was ultimately chosen due to better agreement of estimated equilibrium biomass with observations (not shown).

The actual vegetation (AV) was created by continuing the simulation that produced the potential vegetation, and assumed that the starting year was 1900. This simulation was continued for another 108 years (until 2008) while incorporating human driven land-use change. Throughout the 508 year potential vegetation spin-up, as well as the 108 year continuation with human land use, the atmospheric carbon dioxide concentration was held constant at $378 \mathrm{ppm}$, which 
approximates concentrations at the turn of the millennium (present day).

The model applies human land use by reading an externally compiled data set of land-use transition matrices (Albani et al., 2006) that defines the area fractions of which various land-cover types will change to another type over the course of the year. Two external data sets are used to create the land-use transition matrices, the global land-use data set (GLU) (Hurtt et al., 2006) and the SIMAMAZONIA-1 data set (Soares-Filho et al., 2006). The GLU data set incorporates the SAGE-HYDE 3.3.1 data set and provides land-use transitions in its native format globally, on a $1^{\circ}$ grid from the years 1700 to $1999^{2}$. The SIMAMAZONIA 1 product provides a more intensive assessment of forest cover and deforestation focused in the Amazon Basin, starting in the year 2000. The data is formatted as yearly $1 \mathrm{~km}$ forest cover grids (forest, non-forest, and natural grasslands). The fraction of forest and non-forest cells that fall within each ED2 model simulation grid-cell are counted for each year. This enables the calculation of a rate of change equivalent to the transition matrix format of the GLU data set. The transitions from the GLU data set from 1990 to 1999 were linearly scaled to have continuity with the SIMAMAZONIA data set that is introduced in 2000. Land use reported in the GLU data prior to 1900 were lumped into a single combined transition and applied at the year 1900. A map of the fraction of the land surface containing human land use is provided (see Fig. 1).

Regional maps of above-ground biomass for the potential vegetation (PV) scenario and the differences between the two scenarios (actual vegetation-potential vegetation, or AV-PV) are provided in Fig. 2. The majority of aboveground biomass in the potential simulation is concentrated in the Amazon Basin and the Atlantic Forest of southern Brazil. Late successional broadleaf evergreens comprise most of the above-ground biomass in these regions. Early successional broadleaf evergreens are a prevalent but secondary contributor to biomass in the Amazon Basin. The early succession's contribute the majority of biomass in Cerrado (savanna like ecosystem, mixed open canopy forests with grasses) ecotones found roughly in central Brazil on the southern border of the Amazon rain-forest. This is consistent with their competition and resource niche which emphasizes fast growth and colonization of disturbed areas (such as fire and drought prone Cerrado). The model-estimated equilibrium aboveground biomass (AGB) and basal area (BA) that represent the initial condition are compared with a collection of census measurements in Baker et al. (2004a, b) (see Appendix B).

\footnotetext{
${ }^{2}$ The use of the SAGE-HYDE 3.3.1 global land-use data set acknowledges the University of New Hampshire, EOS-WEBSTER Earth Science Information Partner (ESIP) as the data distributor for this data set.
}

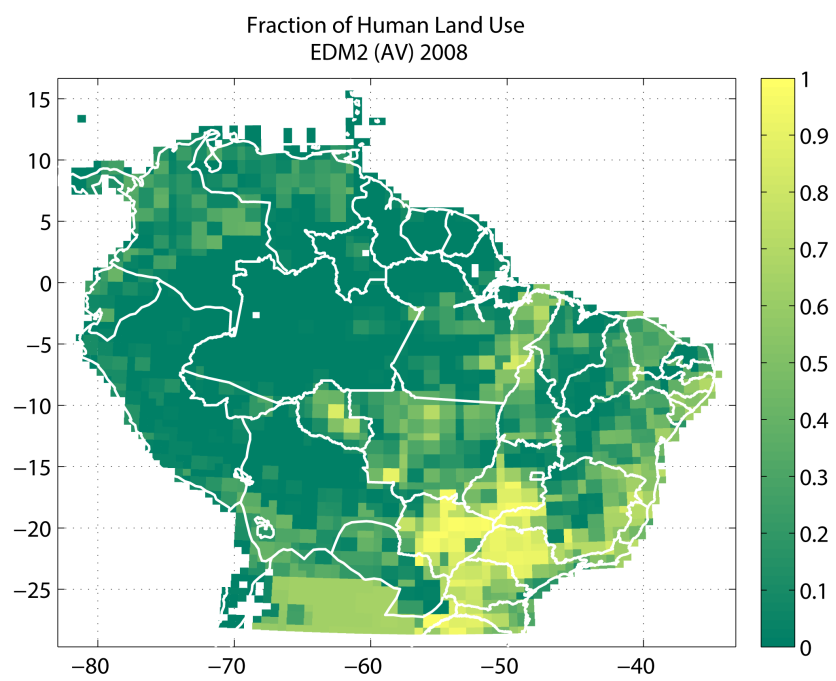

Figure 1. Fraction of the land surface with human land use. Output is taken from the ED2 the actual vegetation (AV) simulation, which was driven with global land-use (GLU) and SIMAMAZONIA-1land-use transition data.

\subsection{Land-atmosphere coupled simulations}

The two coupled land-atmosphere simulations were conducted over 4 years, from January 2002 through December 2005 . These 4 years were chosen because of the availability of lateral boundary conditions and validation data sets. With the exception of differing vegetation structure at the lower boundary, the lateral boundary conditions, model parameters, initialization of the atmospheric state, and timing are all identical between the two. The lateral boundary conditions (air temperature, specific humidity, geopotential, meridional wind speed, zonal wind speed) are taken from the European Centre for Medium Range Weather Forecasting's Interim Reanalysis (ERA-Interim) product (Dee et al., 2011). The data is interpolated from the ERA-Interim's model native Reduced Gaussian Grid (N128, which has an equatorial horizontal resolution of $0.75^{\circ}$ ).

The actual and potential boundary conditions utilized a dynamic model process to generate structure and composition. However, when applied to the coupled simulations, the land-surface dynamics including the processes of mortality, recruitment and growth are turned off and only phenology is left to vary in time. The motivation for this decision is to create a more simple comparison and efficient simulation. Further, the length of the coupled simulations are not long enough to generate large changes in above-ground biomass. As an example, Lewis (2006) and Baker et al. (2004a) estimate that in recent decades, the Amazon has sequestered approximately $0.6 \pm 0.2 \mathrm{Mg} \mathrm{Cha}^{-1} \mathrm{yr}^{-1}$. Over a course of 4 years, this is less than $3 \mathrm{MgCha}^{-1}$, which is on the order of $1-2 \%$ of total forest biomass. 
Table 2. Run time parameters and specifications in the ED2-BRAMS coupled simulations.

\begin{tabular}{|c|c|}
\hline Specification & Value \\
\hline $\begin{array}{l}\text { Simulation period } \\
\text { Grid projection }\end{array}$ & $\begin{array}{l}\text { January 2002-December } 2005 \\
\text { polar stereographic }\end{array}$ \\
\hline Grid dimensions & $98^{\circ}(\mathrm{E}-\mathrm{W}), 86^{\circ}(\mathrm{N}-\mathrm{S}), 56^{\circ}$ (vertical) \\
\hline Horizontal grid resolution & $64 \mathrm{~km}$ \\
\hline Vertical grid resolution & $110 \mathrm{~m}$ (lowest) stretching to $1500 \mathrm{~m}$ at $7 \%$ \\
\hline Atmospheric time step & $30 s$ \\
\hline Atmospheric acoustic time step & $10 \mathrm{~s}$ \\
\hline Land-surface model time step & $120 \mathrm{~s}$ \\
\hline $\begin{array}{l}\text { Method of calculating } \\
\text { Updraft base }\end{array}$ & $\begin{array}{l}\text { level of maximum sum of mean } \\
\text { and variance of vertical velocity }\end{array}$ \\
\hline Number of prototype cloud scales & 2 \\
\hline Mean radius of cloud 1 & $20000 \mathrm{~m}$ \\
\hline Minimum depth of cloud 1 & $4000 \mathrm{~m}$ \\
\hline Mean radius of cloud 2 & $800 \mathrm{~m}$ \\
\hline Minimum depth of cloud 2 & $80 \mathrm{~m}$ \\
\hline Cumulus convective scheme & Grell and Dévényi (2002) \\
\hline Cumulus convective trigger & $\begin{array}{l}\text { pressure differential between } \\
\text { updraft base and } \mathrm{LFC}^{*}<100 \mathrm{hpa}\end{array}$ \\
\hline Cumulus dynamic control & Kain and Fritsch (1990), Kain (2004) \\
\hline $\begin{array}{l}\text { Condensate to precipitation } \\
\text { conversion efficiency }\end{array}$ & $3 \%$ \\
\hline $\begin{array}{l}\text { Cloud \# concentrations } \\
\text { and distribution parameters }\end{array}$ & Medvigy et al. (2010) \\
\hline Turbulent closure & Nakanishi and Niino (2006) \\
\hline Shortwave radiation scattering & Harrington and Olsson (2001) \\
\hline Longwave radiation scattering & Chen and Cotton (1983) \\
\hline Advection & $\begin{array}{l}\text { monotonic, Walcek and Aleksic (1998) } \\
\& \text { Freitas et al. (2012) }\end{array}$ \\
\hline Cumulus feedback on radiation? & yes \\
\hline
\end{tabular}

A group of modeling parameters associated with convective parameterization and the radiation scattering of convective clouds were tuned using a manual binary search procedure. The parameters of mean cloud radius, mean cloud depth, cumulus convective trigger mechanism, dynamic control method and the condensate to precipitation conversion efficiency were calibrated against the Tropical Rainfall Measurement Mission 3B43 product and the surface radiation from the Global Energy and Water Cycle ExperimentSurface Radiation Budget (SRB) product version 2.5. Fitness metrics include monthly mean spatial bias, mean squared error and the variance ratios (i.e., the spatial variance of mean model output over the spatial variance of the observations). Manual binary search calibration was chosen because of the complexity of the parameter space, the need for human supervision and sanity checks, and the non-trivial computation requirements for each simulation. Fifty-four iterations were performed, utilizing a reduced domain in the first group of iterations to facilitate a more rapid calibration. A table of the finalized coupled model runtime conditions is provided 

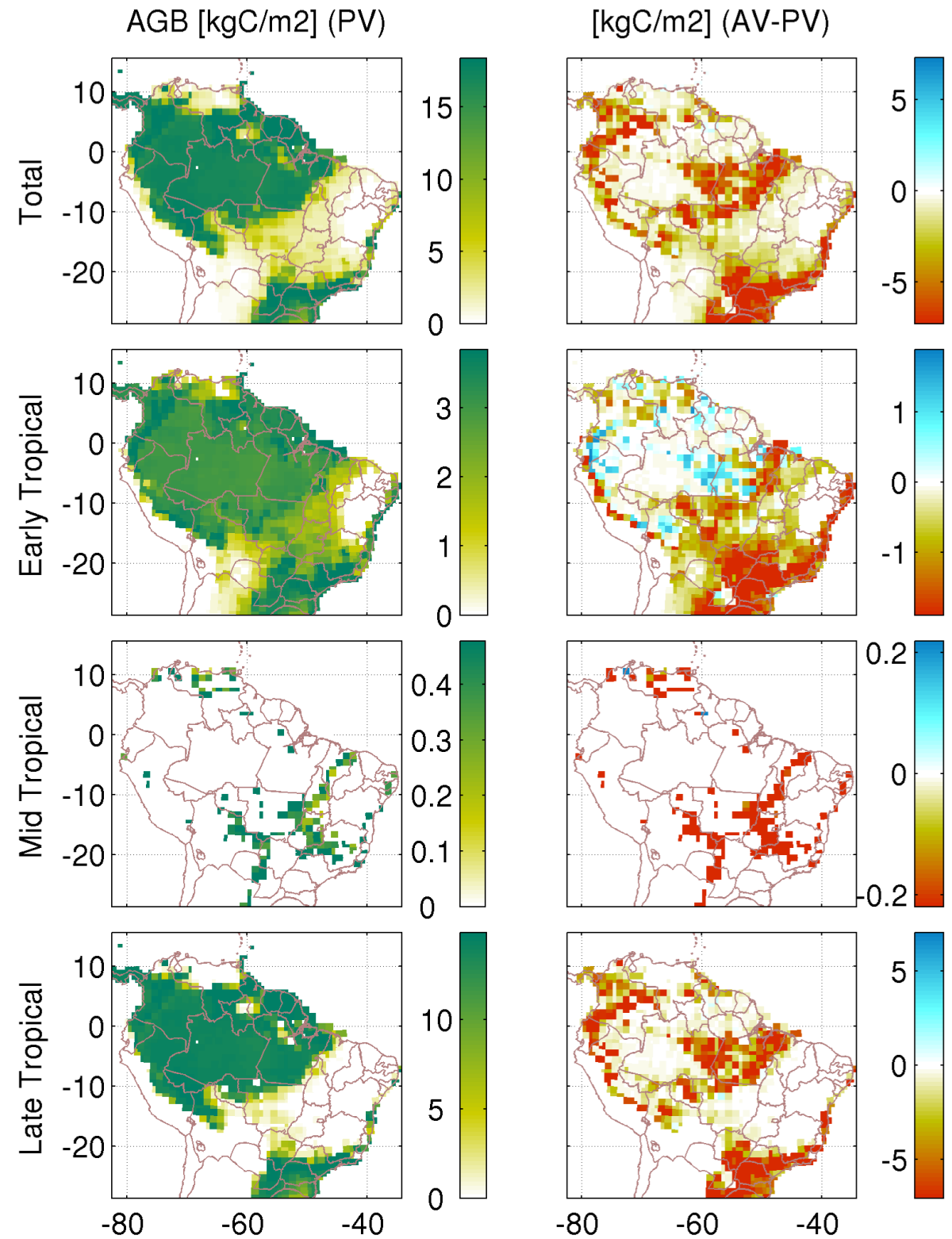

Figure 2. Regional maps of total above-ground biomass (AGB) $\left(\mathrm{kg} \mathrm{m}^{-2}\right)$ from the ED2 initial condition. The left column indicates results are from the potential vegetation condition, the right column is the relative differences between the actual and potential scenarios, (AGB $\mathrm{AV}^{-}$ $\left.\mathrm{AGB}_{\mathrm{PV}}\right)$. Each row represents the partitioning of the above-ground biomass into respect plant functional types. "Early Tropical", "Mid Tropical" and "Late Tropical" refer to broadleaf tropical evergreen plant functional types.

in Table 2. Model output was then compared with observations of atmospheric thermodynamic variables, mean regional surface fluxes (precipitation, radiation, latent heat flux and sensible heat flux) and mean cloud cover profiles; these comparisons are provided in Appendices $\mathrm{C}-\mathrm{F}$, respectively.

\section{Regional analysis of the actual and potential scenarios}

The following analysis of results will repeatedly refer to anomalies, here defined as the subtracted differences of the potential vegetation scenario model output from the actual vegetation scenario model output (or alternatively, AV-PV). 


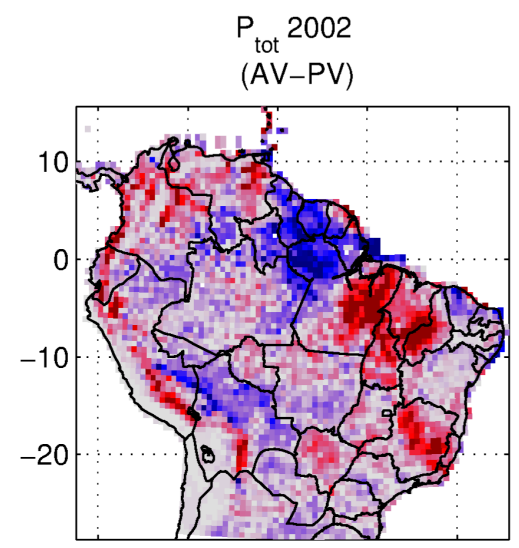

$P_{\text {tot }} 2004$

(AV-PV)

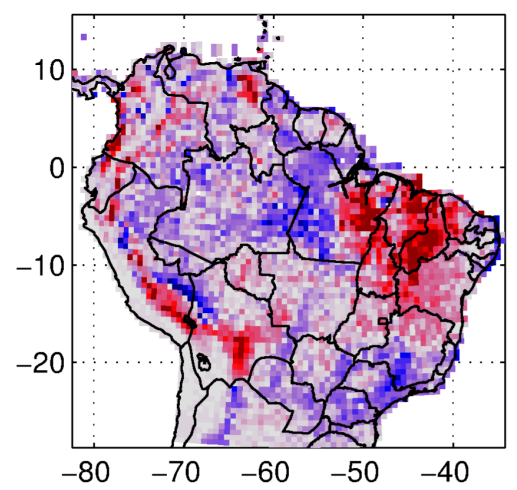

$P_{\text {tot }} 2003$

(AV-PV)
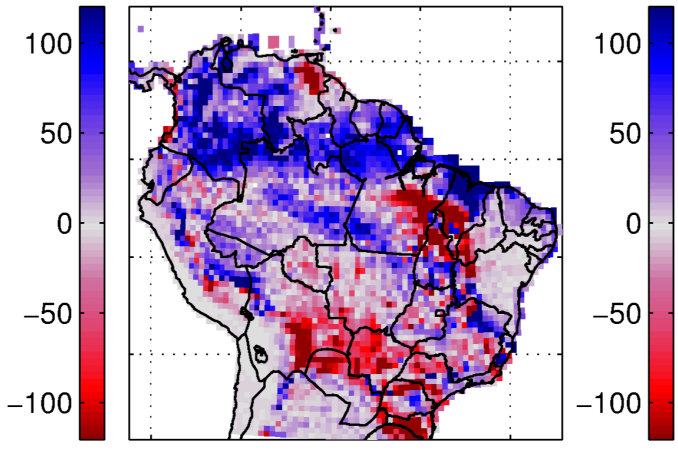

$P_{\text {tot }} 2005$

(AV-PV)
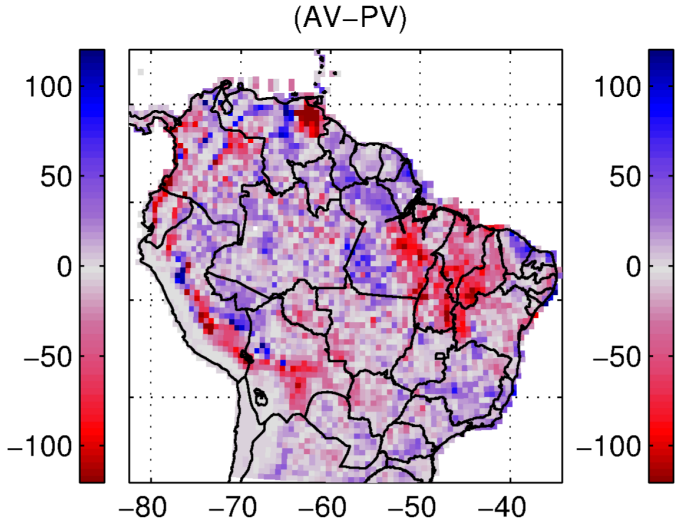

Figure 3. Differences in total annual surface precipitation ( $\mathrm{mm}$ ), 2002-2005. The potential vegetation (PV) condition is subtracted from the actual vegetation $(\mathrm{AV})$ condition, (AV-PV).

\subsection{Emergence of patterning and continental biases}

The annual precipitation accumulations for each simulation were mapped in space and the anomalies between the two were compared for consistent patterning (see Fig. 3). Each anomaly appears to feature a dipole structure with a positive lobe (more actual scenario precipitation) in the north and west of the Amazon delta, and a negative lobe in the south and east of the Amazon delta region. Pattern differences also appear on the Peruvian-Bolivian border, although whether or not it can be considered a dipole is left to the reader. In each year, the precipitation anomaly shows increases on the foothills of the Andes Mountains in southern Peru and the northern tip of Bolivia. There is also a negative anomaly in precipitation in southern and central Bolivia. However, in each year there is also noise among the pattern. For instance in 2002, 2003 and 2005, there are locations in southern Bolivia that show increases in the precipitation anomaly adjacent to the area of decrease.

The patterning in downwelling shortwave surface radiation showed opposite behavior to that of precipitation (not shown), the response is strongly influenced by increased cloud optical depth where convective precipitation has in- creased, and vice-versa. The atmospheric model did not incorporate dynamics of aerosols or atmospheric gases other than multi-phase water; therefore, variability in multi-phase water explains the variability and differences seen in optical depth. Maximum mean annual differences in surface irradiance peak at about $10 \mathrm{~W} \mathrm{~m}^{-2}$, and are strongest over the dipole associated with the precipitation anomaly, as well as over the eastern Brazilian dry lands $\left(41^{\circ} \mathrm{W}\right)$.

The mean annual continental bias in accumulated precipitation, evapotranspiration and total runoff is presented in Fig. 4. There is little evidence of an overall continental bias in accumulated precipitation. However, the human land-use scenario generated a negative continental evapotranspiration anomaly and a positive runoff anomaly in each of the 4 years. Consistent patterning in evapotranspiration and transpiration anomaly were also evident (see Fig. 5). Generally speaking, a negative anomaly in transpiration and total evapotranspiration is evident over the "arc of Amazonian deforestation" (starting at $48^{\circ} \mathrm{W} 2^{\circ} \mathrm{S}$ going clockwise to $62^{\circ} \mathrm{W} 10^{\circ} \mathrm{S}$, also see forest biomass differences in Fig. 2). The spatial correlation between the biomass and evapotranspiration anomalies $\left(R^{2}=0.4\right)$, suggests that the variability in evapotranspiration cannot be explained purely by first order effects from 

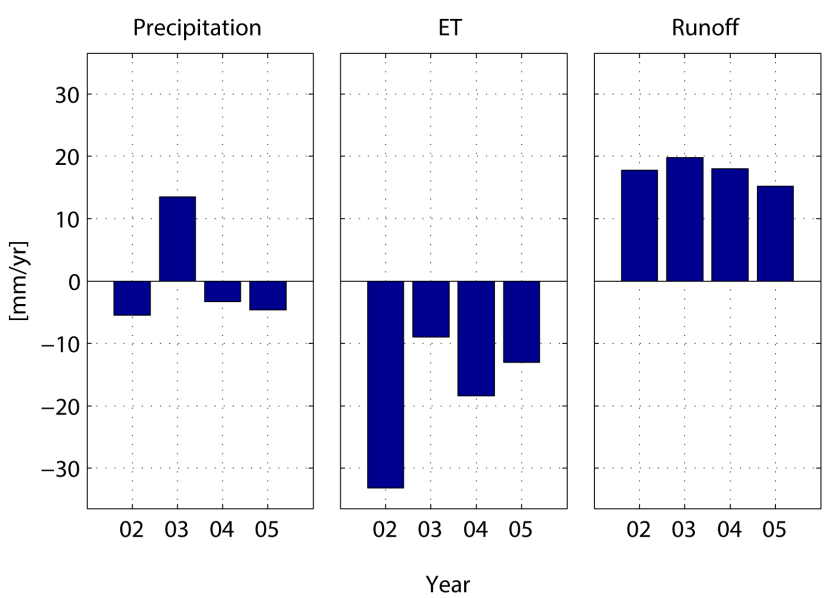

Figure 4. Difference in mean continental precipitation, evaporation and total runoff, between the actual vegetation case and potential vegetation case (AV-PV).

changes to forest structure. Second order effects and complex system feedbacks account for a portion of the variability. These effects include differences in precipitation, and potentially the effects of differences in surface heating and turbulent transport of scalars (heat and water).

\subsection{Connecting hydrologic anomalies and ecosystem response}

The availability of root-zone soil moisture, photosynthetically active radiation (PAR) and nutrients are examples of resource limitations that can potentially mediate the response of vegetation to changes in climate. Light and water are critical limiters of plant growth, disturbance (particularly through fire), and mortality (which can be functionally related to growth). However, the significance of these limiters in how they may drive ecosystem response is dependent on various factors other than the mean, such as the consistency of change (inter-annual variance), when the changes occur (seasonality) and how large the differences are relative to the total. A standard score " $\zeta$ " is one way to evaluate consistency, calculated as the inter-annual mean difference (denoted by brackets " $<>$ ") divided by the first standard deviation of the normalized difference $\eta$ of variable $x$ for year $t$ (mean annual precipitation or downwelling shortwave radiation).

$\eta_{(t)}=\frac{x_{\mathrm{AV},(t)}-x_{\mathrm{PV},(t)}}{0.5\left(x_{\mathrm{AV},(t)}+x_{\mathrm{PV},(t)}\right)}$

$\zeta=\frac{\langle\eta\rangle}{\sigma_{\eta}}$

The spatial maps of the standard scores for precipitation and shortwave radiation anomalies are provided in the upper panels of Fig. 6. For reference, a standard difference of 1 suggests that the normalized difference is equal to its interannual standard deviation. The maps indicate that the dif- ferences in precipitation and radiation from the two scenarios are relatively consistent at the two locations previously identified (Pará Brazil and northern Bolivia). They also indicate that the negative precipitation anomaly, and the positive radiation anomaly over the regions of intense deforestation (i.e., the arc of deforestation) are consistent.

The susceptibility of ecosystems to anomalous precipitation forcing may be derived from an ED2 model mechanic called the "moisture stress index" (MSI). This metric is simply the fraction of time that ED2 vegetation cohorts (plants) are actively keeping their stomata closed due to water limitations. For an ecosystem with $N$ plant groups (also known as cohorts) indexed $i$, the mean land-surface moisture stress index is calculated by the leaf area index (LAI) weighting of the open-fraction $f_{\mathrm{o}}^{\prime}$ of stomata for each plant group in the community. Brackets " $<>$ " denote an averaging in space and time. The stomatal open fraction $f_{\mathrm{o}}^{\prime}$, is based on the ratio of the plant's "demand" for root zone soil moisture, and the "supply" of water the roots are capable of extracting at that time. The demand requirement is driven by the maximum transpiration the plant would generate given the existing light, carbon and vapor pressure conditions with unlimited soil moisture.

$\mathrm{msi}=1-\left\langle\frac{\sum_{i=1}^{N} \operatorname{LAI}_{(i)} f_{\mathrm{o}(i)}^{\prime}}{\sum_{i=1}^{N} \operatorname{LAI}_{(i)}}\right\rangle$

$f_{\mathrm{o}(i)}^{\prime}=\frac{1}{1+\frac{\text { Demand }}{\text { Supply }}}$

Vegetation communities that have experienced high moisture stress indices in the past are more likely to respond structurally to changes in precipitation, because subsequent changes in soil moisture availability will have immediate impacts on photosynthesis and the assimilation of carbon. The lower left panel of Fig. 6 shows the mean moisture stress index for the actual vegetation scenario. The lower right panel of Fig. 6 shows a map of above-ground biomass as a reference to the extents of the modeled Amazon tropical forests. Moisture stress is low in areas where there is copious precipitation (the supply term). Note that in the interior of the Amazon Basin, moisture stress has little to no influence on stomatal regulation (and subsequently photosynthesis). The open canopy dry forests in southern Brazil an Bolivia, as well as the Cerrado, have higher moisture stress.

\section{Hydrometeorological focus areas - Pará Brazil and the Gran Chaco}

Two locations that coincide with the pattern differences in precipitation are highlighted in Fig. 6. Each location shows decreases in normalized precipitation and increases in down- 


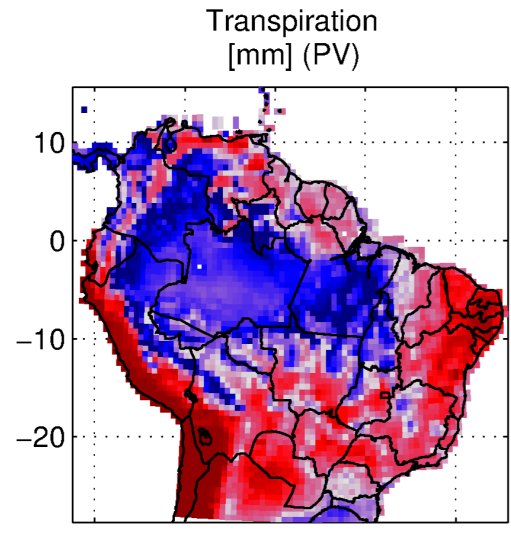

ET

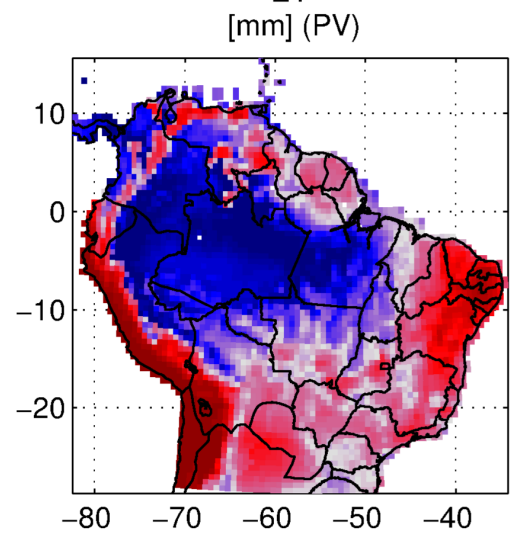

Transpiration Difference (AV-PV)

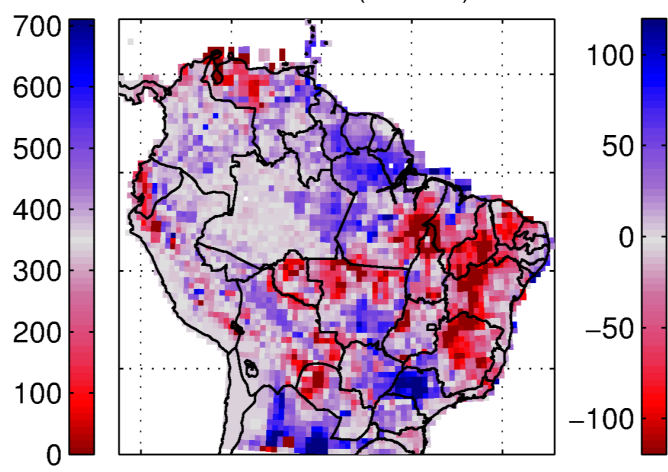

ET Difference $(\mathrm{AV}-\mathrm{PV})$
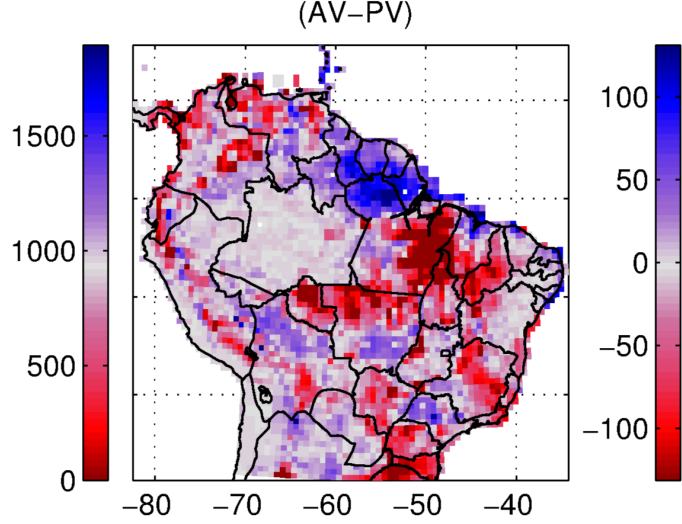

Figure 5. Left panels: mean annual transpiration and evapotranspiration in the potential vegetation (PV) scenario, from 2002 to 2005 (mm). Right panels: difference in mean annual transpiration and evapotranspiration between the actual vegetation case and potential vegetation case (AV-PV).

welling shortwave radiation associated with the actual vegetation scenario. The vegetation of these locations also show a degree of seasonal moisture stress according to the MSI metric presented in section 3.2. One site is centered on $4.5^{\circ} \mathrm{S}$ $50.5^{\circ} \mathrm{W}$ in the Brazilian state of Pará. The other site is centered on $19.5^{\circ} \mathrm{S} 63.5^{\circ} \mathrm{W}$ in the northwestern part of the Bolivian Gran Chaco where it meets the Andes mountains (sometimes referred to as the Montane Gran Chaco). These two locations are chosen as areas of focused evaluation of hydrology and hydrometeorology. For simplicity, these will be referred to as the Pará and Gran Chaco focus areas.

A representation of the vegetation demographics at the centroids of the two focus areas, as estimated by the ED2 model, are provided in Fig. 7. The natural landscapes at the Pará focus areas are dominated by tropical evergreen forests, and are close to (but not within) the ecotone transition between tropical forests and Cerrado. The offline model spin-up of the actual vegetation scenario imposed pastures on approximately one-third of the land-cover. Roughly $10 \%$ of the landscape contains old-growth forests that have gone 200 years since the last disturbance. The focus area in the Gran Chaco is located in a region influenced by the outlet of the South American Low Level Jet. The continental precipitation recycling ratio in this area is relatively high compared to the rest of the continent (Eltahir and Bras, 1994). This exact location in the Gran Chaco is a dry forest ecosystem that borders adjacent ecotones of tropical rainforests to the north, montane ecosystems to the west and grasslands to the south. The ED2 model estimated a potential vegetation demographic that is fairly consistent with the depiction of dry forests, a sparse cover of short trees with grasses in the understory. The actual vegetation simulation of the Gran Chaco, driven by the GLU data set (Hurtt et al., 2006), forced $25 \%$ of the natural landscape to pasture (grasses), with an accompanying $20 \%$ of abandoned and degraded lands. Human land use, as represented in the ED2 model at this specific location, led to a collapse of the estimated tree cover, which includes natural landscapes. This specific site is undoubtedly a more aggressive representation of the differences between the $a c$ tual and potential scenario ecosystems in this region. As a whole, of course, human land-conversion has not lead to a collapse of the Gran Chaco's dry-forest ecosystems. 

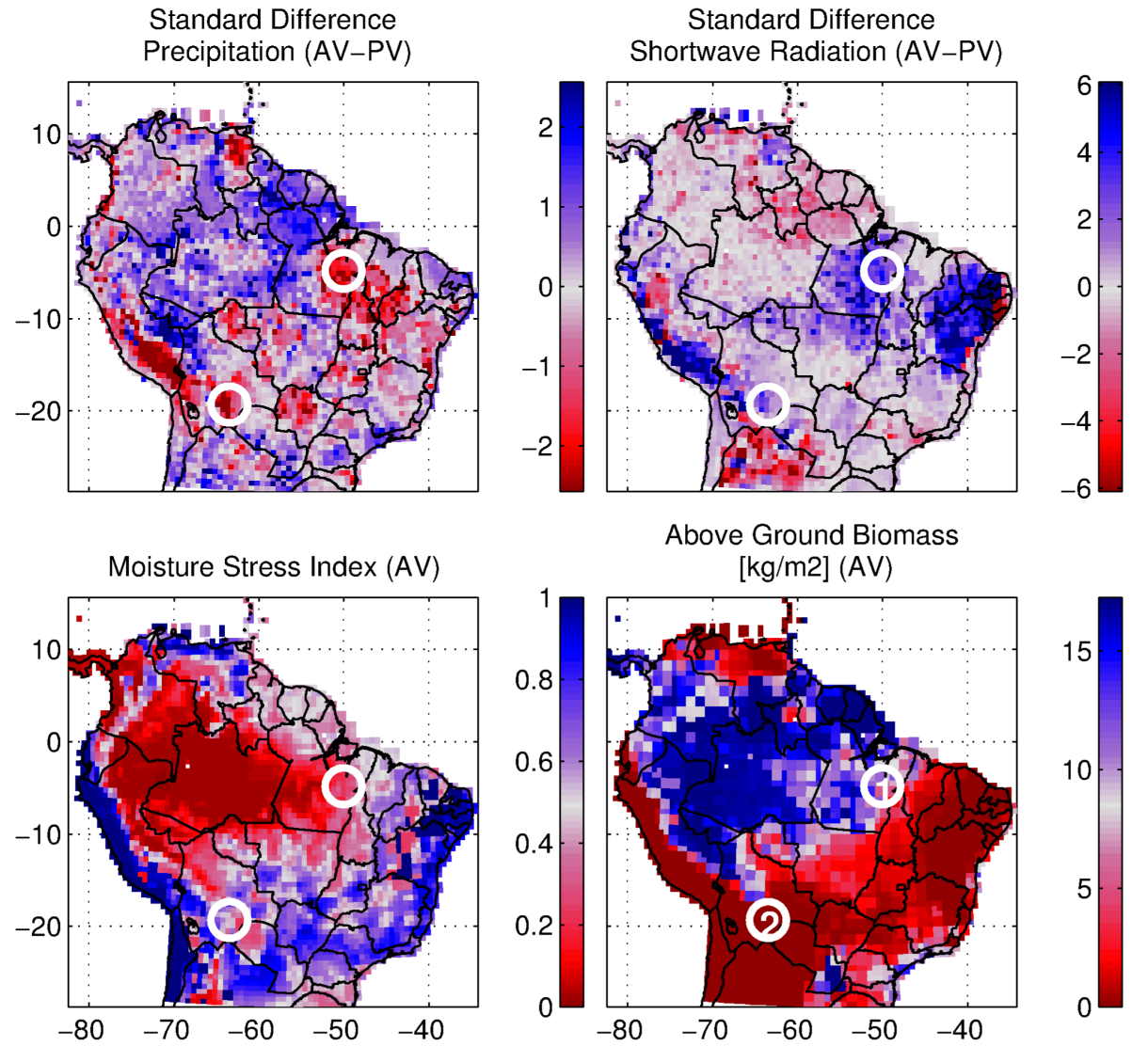

Figure 6. Combined assessment of the regional significance in differences between precipitation and radiation, and the susceptibility of the ecosystems. Upper panels show standard scores for consistency of differences actual and potential (AV-PV) surface precipitation and surface downwelling shortwave radiation. The lower left panel shows the moisture stress index for the actual (AV) scenario, see Eq. (3). For reference, actual (AV) scenario above-ground biomass is provided in the bottom right panel.

\subsection{Canopy water and energy balance - Pará}

Simulated annual precipitation at the Pará focus area was typically around $1500 \mathrm{~mm} \mathrm{yr}^{-1}$, the surface energy flux was dominated by leaf evaporation and transpiration. Transpiration dominated vapor flux in the dry season (MayNovember). Runoff in the form of drainage through the lower soil column occurred mostly during the wet season. The time series water and energy balance at the land-surface is summarized in Fig. 8. Accumulated water fluxes from the potential vegetation scenario are shown in the upper left panel a, anomalous accumulations are shown in the upper right panel $b$. The actual vegetation scenario experienced roughly $10 \%$ less surface precipitation at the Pará focus area. However, the site experienced a small net increase $\left(30 \mathrm{~mm} \mathrm{yr}^{-1}\right)$ in precipitation throughfall, due to a proportionally stronger decrease in leaf interception surfaces. There is also increased drainage in the actual vegetation scenario, which appears to be symptomatic of both increased throughfall and the decrease in the root-zone soil-moisture sink from transpiration.
The actual vegetation scenario receives more total shortwave and longwave radiation $\left(R_{\mathrm{SD}}+R_{\mathrm{LD}}\right)$, which is directly attributable to the decrease in mean convective cloud albedo associated with the decrease in convective rainfall at the site. Although the site receives more total incoming radiation in the actual vegetation simulation, the surface albedo increases with the conversion of forests to pasture. This results in more reflected radiation and a decrease in combined sensible and latent heat flux $(H+L)$, see the bottom right panel $\mathrm{d}$ of Fig. 8.

\subsection{Canopy water and energy balance - Gran Chaco}

The annual precipitation at Gran Chaco in the potential simulation ranged from 500 to nearly $1000 \mathrm{~mm}$. Annual precipitation was roughly $15 \%$ lower in the actual vegetation simulation. A summary of the hydrologic response and the anomalies are shown in Fig. 9. Like the Pará site, landconversion drove a decrease in leaf area, and therefore a significant decrease in leaf interception of precipitation in the actual (AV) simulation. However, in this case, the relative decrease in interception surfaces due to deforestation 

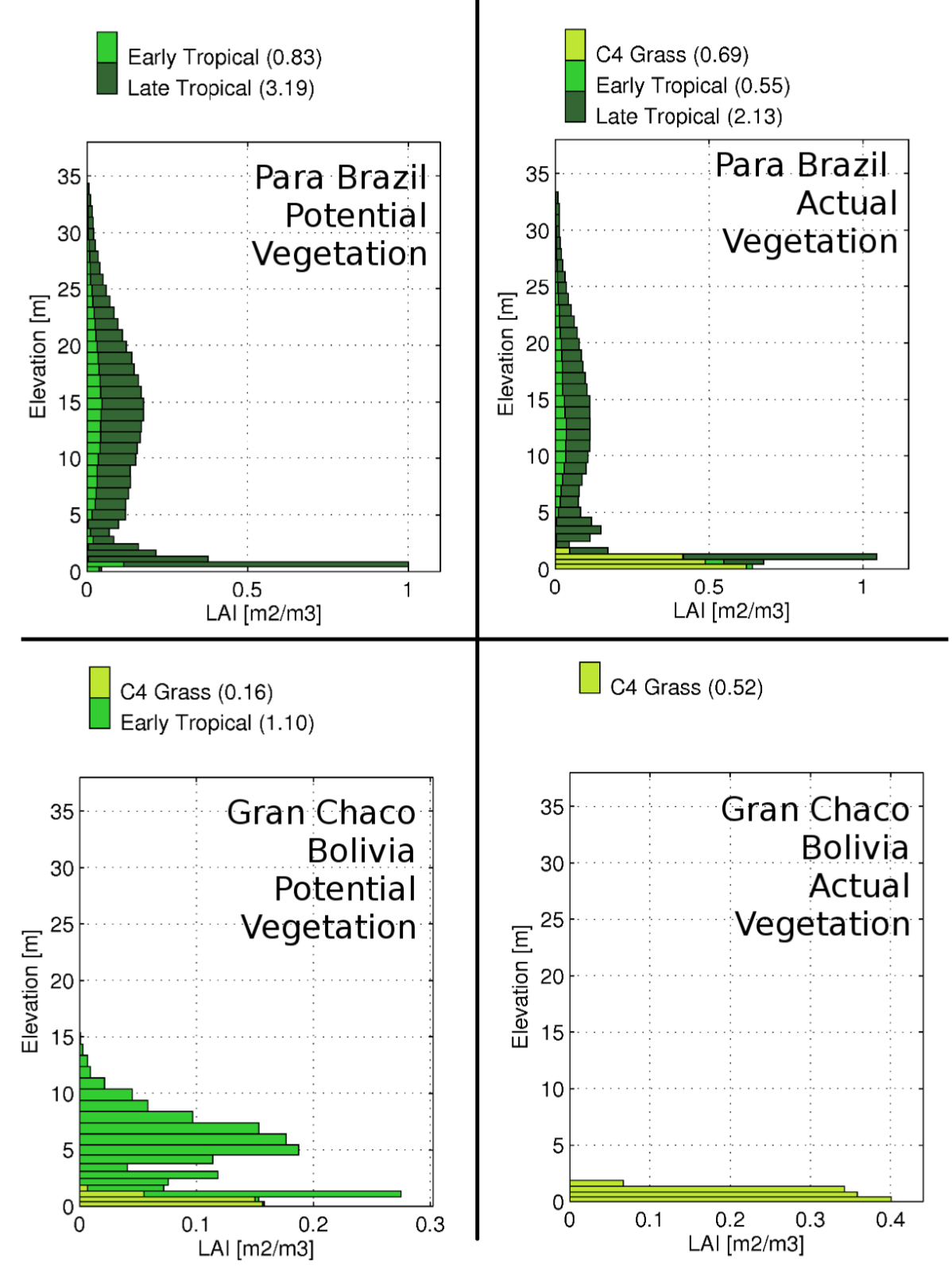

Figure 7. Mean vertical leaf area index profiles $\left(\mathrm{m}^{2} \mathrm{~m}^{-3}\right)$ estimated by the ecosystem demography model 2 at the two focus areas. Vertically integrated leaf area index $\left(\mathrm{m}^{2} \mathrm{~m}^{-2}\right)$ per each represented functional type of plant is shown in the key above each plot.

was less affecting than the decrease in total precipitation due to land-atmosphere feedbacks. Therefore, the actual vegetation simulation experienced a decrease in total precipitation throughfall. Soil evaporation accounted for half of the water losses, while leaf evaporation and transpiration equally combined to represent the other half. The relatively low precipitation rates promoted almost no detectable runoff. Transpiration decreased by $20 \%$ in the actual simulation, which is a direct consequence of decreased stomatal density and precipitation throughfall.
Notwithstanding the decreased precipitation throughfall in the actual simulation, surface evaporation increased. Despite decreased precipitation throughfall, upper soil-column moisture from rain events has a longer residence time in the root zone, as shown in Fig. 10. This is an effect of decreased transpiration, and thus moisture in the grass root zone lasts comparatively longer into the dry season. Note that the relative reduction in precipitation throughfall nearly balanced the reduction in transpiration. There is little evidence to suggest that increased soil evaporation rates would maintain indef- 

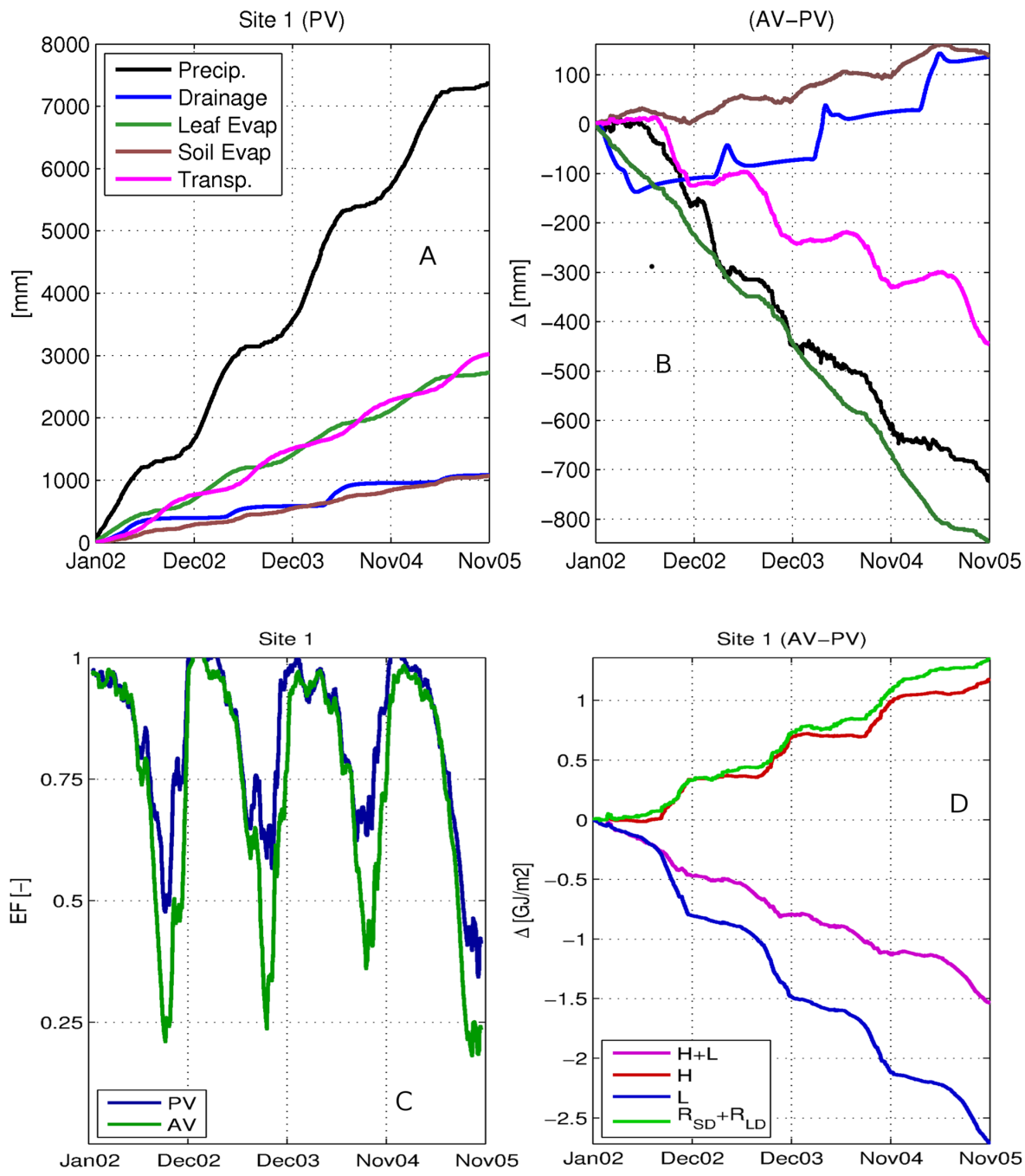

Figure 8. Time series analysis of the surface water and energy balance at the Pará focus site, 2002-2005. (a) Accumulated water flux for the potential scenario. (b) Accumulated differential water flux between the actual (AV) and potential (PV) scenarios. (c) Mean evaporative fraction, latent heat flux $(L)$ divided by the sum of latent and sensible $(H)$ heat flux $(L /(L+H))$. (d) Accumulated differential energy flux in gigajoules per square meter. $R_{\mathrm{SD}}$ is downwelling shortwave radiation incident on the surface, $R_{\mathrm{LD}}$ is downwelling longwave radiation incident on the surface.

initely in the actual scenario, which could alternatively be associated with transient changes in soil column storage.

Like the Pará site, land-conversion at Gran Chaco also drove an increase in total surface albedo, a direct effect due to the loss of dark foliage. More incident radiation is reflected, which reduces net radiation. Unlike the Pará focus area, the albedo effect is stronger than the increase in incident radiation, which leads to decreased sensible heat flux (see Fig. 9) and slightly cooler annual surface temperatures (not shown).

\subsection{Land-atmosphere coupling - Pará}

A box is constructed around this site for the month of September 2003 that contains the extents of a continuous space with negative precipitation anomaly (see Fig. 11). Ta- ble 3 shows a selection of spatiotemporal mean indicators from the bounded domain. To summarize the differences in surface fluxes, the results are consistent with the single site time-series analysis, where the actual vegetation scenario experienced a decrease in net radiation $\left(-10 \mathrm{~W} \mathrm{~m}^{-2}\right.$, despite increased incident shortwave radiation) and an increased mean surface albedo.

The decreased precipitation and surface energy flux of the actual scenario are accompanied by a boundary layer with lower equivalent potential temperature (see Fig. 12). The decrease in boundary layer equivalent potential temperature has a strong physical connection to explaining the decrease in precipitation, particularly since the vast majority of the precipitation was generated through the convective parameterization (data not shown). This was verified by recording a 
$\log$ of failures in deep convection (precipitating convective clouds) generated by the convective parameterization. All of the bias in these convective failures occurring in the actual simulation was attributed to the generation of convection that resulted in clouds that were too thin to be classified as precipitating deep convection clouds. This is indicative of the how much convective available potential energy (CAPE) can be released through convective buoyancy, which is controlled by the moist static energy in the surface parcels as well as the moist static energy of the mean atmosphere over the depth of the troposphere. Alternatively, there was no positive bias in the logs associated with the inability to trigger parcel buoyancy.

It is questioned if the driving force behind the reduced equivalent potential temperature profiles of the actual scenario is solely the result of local surface fluxes or caused by changes in the regional energy circulation. Both scenarios net a negative moisture convergence (divergent) budget for the month (total integrated water mass flux through the box boundaries, normalized by the box area). The potential vegetation scenario loses more water $\left(-51.32 \mathrm{~kg} \mathrm{~m}^{-2}\right)$ through its lateral boundaries than the AV scenario $\left(-37.14 \mathrm{~kg} \mathrm{~m}^{-2}\right)$, see Table 3. This can be visualized by flux vectors as well (see Fig. 13). In the potential vegetation case shown in the left panel, the flow vectors run east-to-west and up the gradient, which means the advecting air mass is gaining moisture and is consistent with the net water divergence described in Table 3.

\subsection{Land-atmosphere coupling - Gran Chaco}

Similar to the case study in Pará, a bounding box was constructed around the Gran Chaco site in April 2003 that captures a spatially continuous negative anomaly in precipitation. The boundaries are shown in black against the mean total and mean anomaly in monthly precipitation and evapotranspiration (see Fig. 14). Mean statistics are shown in Table 4 . The actual scenario experienced less than half as much precipitation ( $41 \mathrm{~kg} \mathrm{~m}^{-2}$ compared to $85 \mathrm{~kg} \mathrm{~m}^{-2}$ ). The evaporation anomaly between the two scenarios was not as strong (111 $\mathrm{kg} \mathrm{m}^{-2}$ in the potential scenario compared to $83 \mathrm{~kg} \mathrm{~m}^{-2}$ for the actual scenario).

The actual vegetation scenario experienced more downwelling shortwave radiation yet less net surface radiation, which was influenced by an increased surface albedo. Like the Pará case, the actual scenario experienced a lower equivalent potential temperature over the boundary layer (see Fig. 15). The convective parameterization logs accounted that the actual scenario experienced a great deal more failed convective events associated with an inability to generate deep clouds (the same reason as the Pará case). Note that the model's cloud depth parameterization is controlled by convective available potential energy. However, in this case, about $25 \%$ of the bias in failures was also explained by an inability to trigger convection. This is interesting because this case was slightly different from the Pará in that the actual scenario did not experience higher levels of turbulent kinetic energy over the boundary layer.

An analysis of moisture convergence and advective flux was used to better understand the local versus regional controls that drive convective precipitation. Both scenarios showed negative moisture convergence, typical during the onset of the dry season in this region, refer to Table 4 . The potential scenario showed less moisture divergence $\left(-37 \mathrm{~kg} \mathrm{~m}^{-2}\right)$ than the actual scenario $\left(-52 \mathrm{~kg} \mathrm{~m}^{-2}\right)$. The moisture advected into the Gran Chaco site comes via northerly winds from the moist Amazonian air mass, see the left panel of Fig. 16. Moisture transport from the north decreases in the actual scenario, see the right panel of Fig. 16.

\section{Discussion}

\subsection{Secondary forests and evapotranspiration patterning}

The maps of evapotranspiration and transpiration anomaly showed pattern similarity with the differences in aboveground biomass, as compared to a lack of pattern similarity between precipitation and above-ground biomass anomalies. The stronger correlation between the evapotranspiration and forest biomass anomalies can be rationalized by understanding how the ED2 model resolves canopy hydrologic process. In ED2, closed canopy tropical broadleaf evergreen forests have higher leaf area indices than grasses, with possible exceptions during drought deciduous leaf drop. Deforestation of closed canopy forests will therefore decrease total leaf area. Rainfall that is intercepted in ED2 has two outcomes: it can either re-evaporate or drip to the land surface (one shortcoming of this assumption is that epiphytes may store water directly from leaf interception). Throughfall precipitation has multiple outcomes: it can evaporate from the surface, become stored in the soil and vegetation indefinitely, or leave via transpiration or leave via runoff. The evaporation rates between the leaf and soil surfaces with canopy air space are regulated by two factors, the aerodynamic resistance and the effective vapor pressure deficit between the respective surfaces with the air space. In the ED2 model formulation, which scales in-canopy wind speeds following Massman (1997), the aerodynamic resistance in the forest canopy will attenuate from top to bottom as wind speeds monotonically decrease. Moreover, water that becomes bound in the soil matrix will have a decreased vapor pressure deficit with the adjacent air (compared to leaf water which is not bound, and assumed saturated) due to the effects of pore spaces at the soil surface (Lee and Pielke, 1992). Therefore in ED2, precipitation that is intercepted in the canopy has both an extra opportunity (simply considering the order of process) to evaporate back to the atmosphere, but also has a tendency towards both de- 

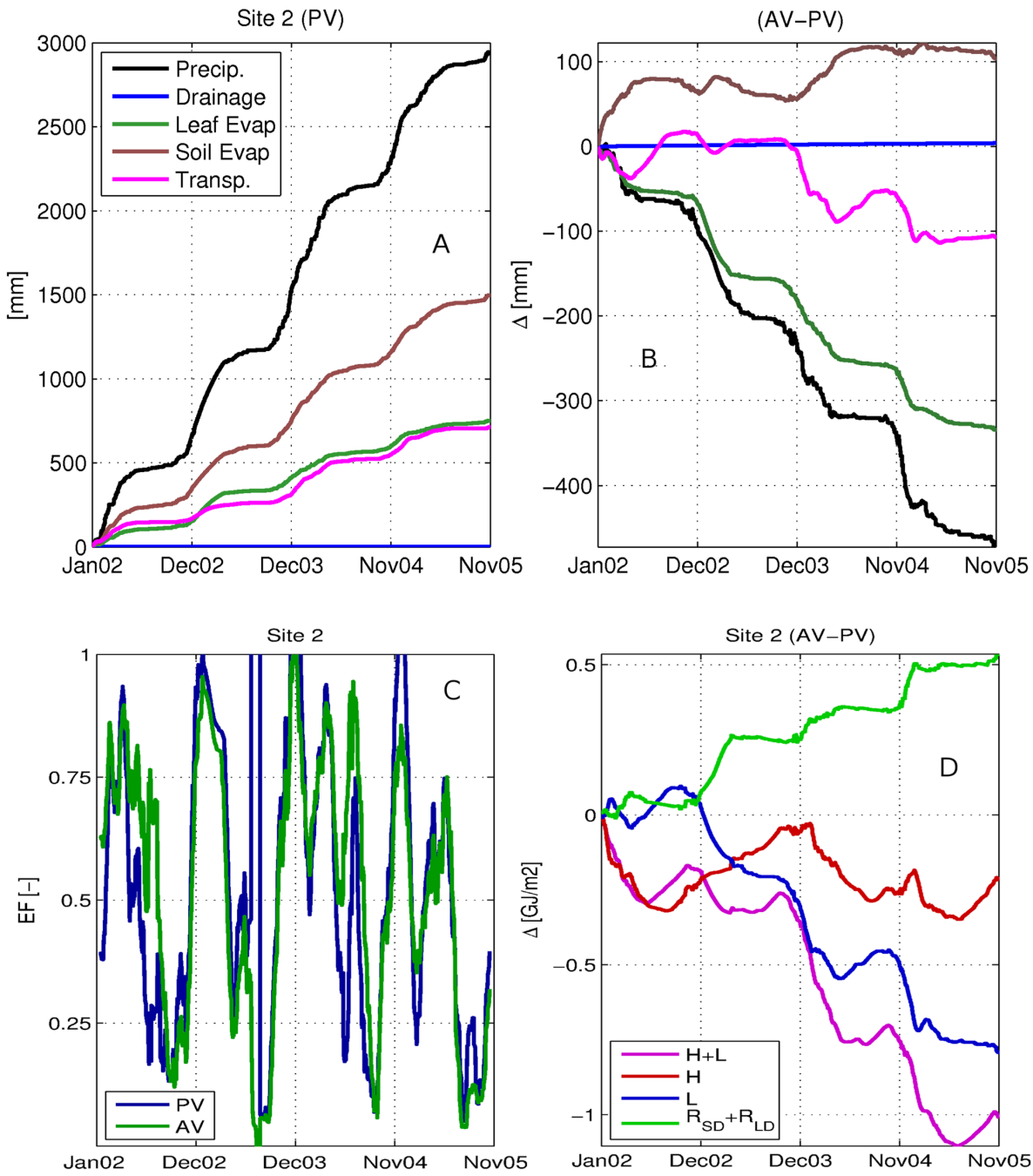

Figure 9. Time series analysis of the surface water and energy balance at the Gran Chaco site, 2002-2005. (a) Accumulated water flux for the potential scenario. (b) Accumulated differential water flux between actual (AV) and potential (PV) scenarios. (c) Mean evaporative fraction, latent heat flux $(L)$ divided by the sum of latent and sensible $(H)$ heat flux $(L /(L+H))$. (d) Accumulated differential energy flux in GigaJoules per square meter. $R_{\mathrm{SD}}$ is downwelling shortwave radiation incident on the surface, $R_{\mathrm{LD}}$ is downwelling longwave radiation incident on the surface.

creased aerodynamic resistance and increased vapor pressure deficit that drives evaporation rate.

However this explanation of process only considers the immediate structural effects of deforestation, which is not static but also has phases of recovery when left unmanaged. During the recovery cycle of tropical forests following natural disturbance, successful new growth in the canopy is typically dominated by pioneer species. Pioneer species have lower wood density, higher maximum photosynthetic capacity and quicker vertical growth than late successional species (Laurance et al., 2004; Poorter et al., 2006; Chave et al., 2006). The canopy leaf area may flush to previous levels within a century, yet it may take several centuries for total forest biomass to rebound. This type of behavior was observed in the model spin-up, where newly disturbed patches of land in the central Amazon reached maximum leaf area over a span of a few decades, compared to the length of time (more than a century) it took for biomass to stabilize.

The results presented here support that secondary forests undergoing recovery from deforestation can drive detectable pattern increases in total transpired water across the region. It is rationalized that at these locations, photosynthetic capacity is scaled by leaf area, as well as a distribution of members skewed towards rapid growth and high photosynthetic capacity. If there is sufficient available soil water there would be an expected increase in total transpiration. In the actual model scenario containing deforestation effects, the model estimated an increase in early successional tropical evergreens (pioneers) in the recovering forests of northern Pará and eastern Amazonas (centered on $5^{\circ} \mathrm{S} 58^{\circ} \mathrm{W}$ ) (see Fig. 2 
Table 3. Hydrologic monthly means within the bounded area above the Pará case study, September 2003. Total change in column precipitable water for the month per square meter $\Delta M_{\mathrm{pw}}$, evapotranspiration ET, precipitation $P$ and resolved moisture convergence Mc, $55 \mathrm{~m}$ air temperature $T$, mixing ration $(55 \mathrm{~m}) r$, equivalent potential temperature $\theta_{\mathrm{e}}$, surface albedo to shortwave radiation $\alpha$, downwelling shortwave radiation $R_{\mathrm{SD}}$, downwelling longwave radiation $R_{\mathrm{LD}}$, upwelling longwave radiation $R_{\mathrm{LU}}$, net surface radiation $R_{\text {net }}$, sensible heat flux SHF and latent heat flux LHF.

\begin{tabular}{lcccccccr} 
& $\begin{array}{c}\text { Case } \\
\text { Units }\end{array}$ & $\begin{array}{c}\Delta M_{\mathrm{pw}} \\
\mathrm{kg} \mathrm{m}^{-2}\end{array}$ & $\begin{array}{c}\mathrm{ET} \\
\mathrm{kg} \mathrm{m}^{-2}\end{array}$ & $\begin{array}{c}P \\
\mathrm{~kg} \mathrm{~m}^{-2}\end{array}$ & $\begin{array}{c}\mathrm{Mc} \\
\mathrm{kg} \mathrm{m}^{-2}\end{array}$ & $\begin{array}{c}T \\
{ }^{\circ} \mathrm{C}\end{array}$ & $\begin{array}{c}r \\
\mathrm{~g} \mathrm{~kg}^{-1}\end{array}$ & \\
\cline { 2 - 8 } & $\mathrm{AV}$ & -3.457 & 63.1 & 29.8 & -37.14 & 32.83 & 12.18 & \\
& $\mathrm{PV}$ & -3.515 & 94.7 & 47.3 & -51.32 & 32.35 & 12.93 & \\
\hline Case & $\theta_{\mathrm{e}}$ & $\alpha$ & $R_{\mathrm{SD}}$ & $R_{\mathrm{LD}}$ & $R_{\mathrm{LU}}$ & $R_{\mathrm{net}}$ & $\mathrm{SHF}$ & $\mathrm{LHF}$ \\
Units & $\mathrm{K}$ & - & $\mathrm{W} \mathrm{m}^{-2}$ & $\mathrm{~W} \mathrm{~m}^{-2}$ & $\mathrm{~W} \mathrm{~m}^{-2}$ & $\mathrm{~W} \mathrm{~m}^{-2}$ & $\mathrm{~W} \mathrm{~m}^{-2}$ & $\mathrm{~W} \mathrm{~m}^{-2}$ \\
\hline AV & 336.8 & 0.262 & 300.2 & 443.3 & 513.2 & 180.9 & 139.25 & 70.97 \\
PV & 338.2 & 0.257 & 285.6 & 443.9 & 498.0 & 187.8 & 114.50 & 106.45 \\
\hline
\end{tabular}

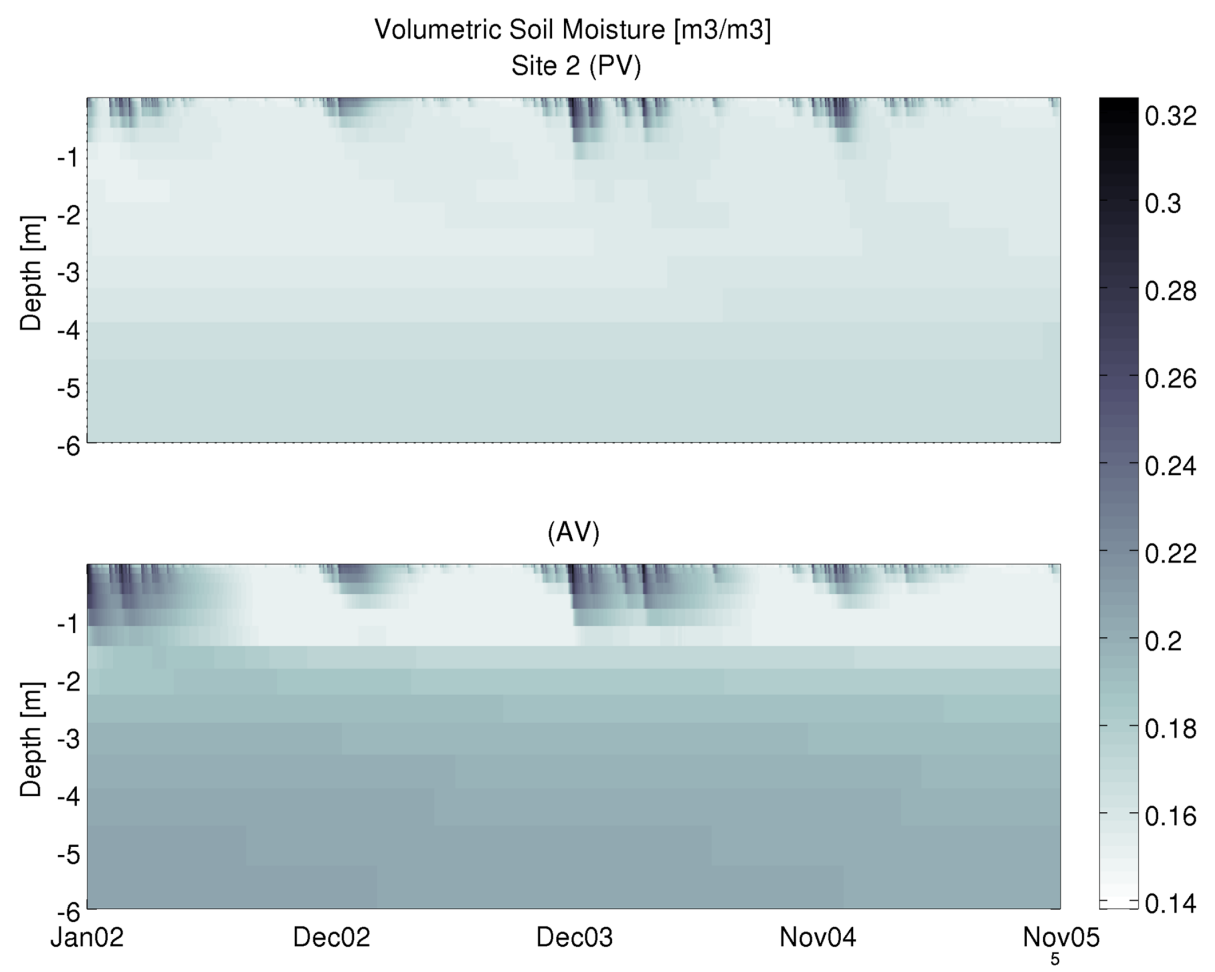

Figure 10. Time series profile of volumetric soil water at the Gran Chaco focus area. Both scenarios, potential (PV) and actual (AV), are shown separately.

second row right panel). There is an increase in regional transpiration here (Fig. 5) that has a strong pattern match with the increase in early successional biomass, moreover there is little evidence of influence from pattern precipitation here (see Fig. 3).

\subsection{Regional surface water balance and runoff generation}

There was a clear and consistent bias in the total annual evapotranspiration (negative) and runoff (positive) estimated in the actual scenario when integrated over the entire domain of northern South America. There is some rudimentary explanation of the first order biases in evapotranspiration explained above. The regional runoff bias appears to have several potential explanations and remaining questions. It is clear that in the actual scenario, decreased canopy interception promotes a first order effect of increased canopy throughfall. However, we saw in comparing the Pará and Gran Chaco case studies that changes in canopy interception can be offset by changes in incident precipitation. Therefore increased canopy throughfall from deforestation is not ubiq- 
Table 4. Hydrologic monthly means within the bounded area above the Gran Chaco case study, April 2003. Total change in column precipitable water for the month per square meter $\Delta M_{\mathrm{pw}}$, evapotranspiration ET, precipitation $P$ and resolved moisture convergence Mc, $55 \mathrm{~m}$ air temperature $T$, mixing ration $(55 \mathrm{~m}) r$, equivalent potential temperature $\theta_{\mathrm{e}}$, surface albedo to shortwave radiation $\alpha$, downwelling shortwave radiation $R_{\mathrm{SD}}$, downwelling longwave radiation $R_{\mathrm{LD}}$, upwelling longwave radiation $R_{\mathrm{LU}}$, net surface radiation $R_{\mathrm{net}}$, sensible heat flux $\mathrm{SHF}$ and latent heat flux LHF.

\begin{tabular}{lcccccccr} 
& $\begin{array}{c}\text { Case } \\
\text { Units }\end{array}$ & $\begin{array}{c}\Delta M_{\mathrm{pw}} \\
\mathrm{kg} \mathrm{m}^{-2}\end{array}$ & $\begin{array}{c}\mathrm{ET} \\
\mathrm{kg} \mathrm{m}^{-2}\end{array}$ & $\begin{array}{c}P \\
\mathrm{~kg} \mathrm{~m}^{-2}\end{array}$ & $\begin{array}{c}\mathrm{Mc} \\
\mathrm{kg} \mathrm{m}^{-2}\end{array}$ & $\begin{array}{c}T \\
{ }^{\circ} \mathrm{C}\end{array}$ & $\begin{array}{c}r \\
\mathrm{~g} \mathrm{~kg}^{-1}\end{array}$ & \\
\cline { 2 - 8 } & $\mathrm{AV}$ & -11.42 & 82.95 & 41.89 & -52.49 & 25.98 & 12.73 & \\
& $\mathrm{PV}$ & -11.02 & 111.89 & 85.91 & -36.99 & 27.36 & 15.15 & \\
\cline { 2 - 8 } Case & $\theta_{\mathrm{e}}$ & $\alpha$ & $R_{\mathrm{SD}}$ & $R_{\mathrm{LD}}$ & $R_{\mathrm{LU}}$ & $R_{\text {net }}$ & $\mathrm{SHF}$ & $\mathrm{LHF}$ \\
Units & $\mathrm{K}$ & - & $\mathrm{W} \mathrm{m}^{-2}$ & $\mathrm{~W} \mathrm{~m}^{-2}$ & $\mathrm{~W} \mathrm{~m}^{-2}$ & $\mathrm{~W} \mathrm{~m}^{-2}$ & $\mathrm{~W} \mathrm{~m}^{-2}$ & $\mathrm{~W} \mathrm{~m}^{-2}$ \\
\hline AV & 334.4 & 0.330 & 252.6 & 400.2 & 466.9 & 111.74 & 38.54 & 91.0 \\
PV & 342.0 & 0.297 & 218.7 & 424.9 & 462.6 & 130.2 & 28.15 & 122.5 \\
\hline
\end{tabular}
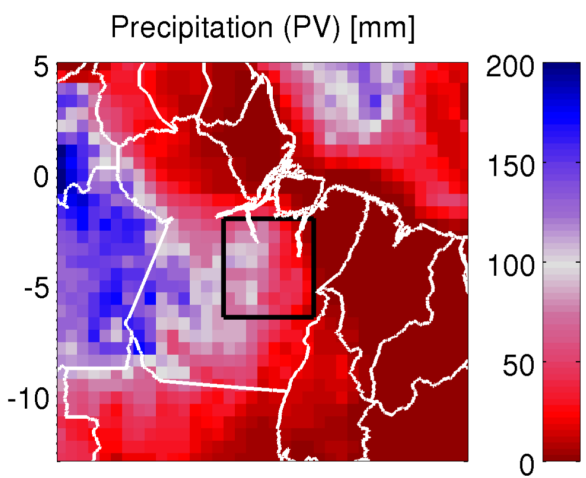

Differential Precipitation (AV-PV)
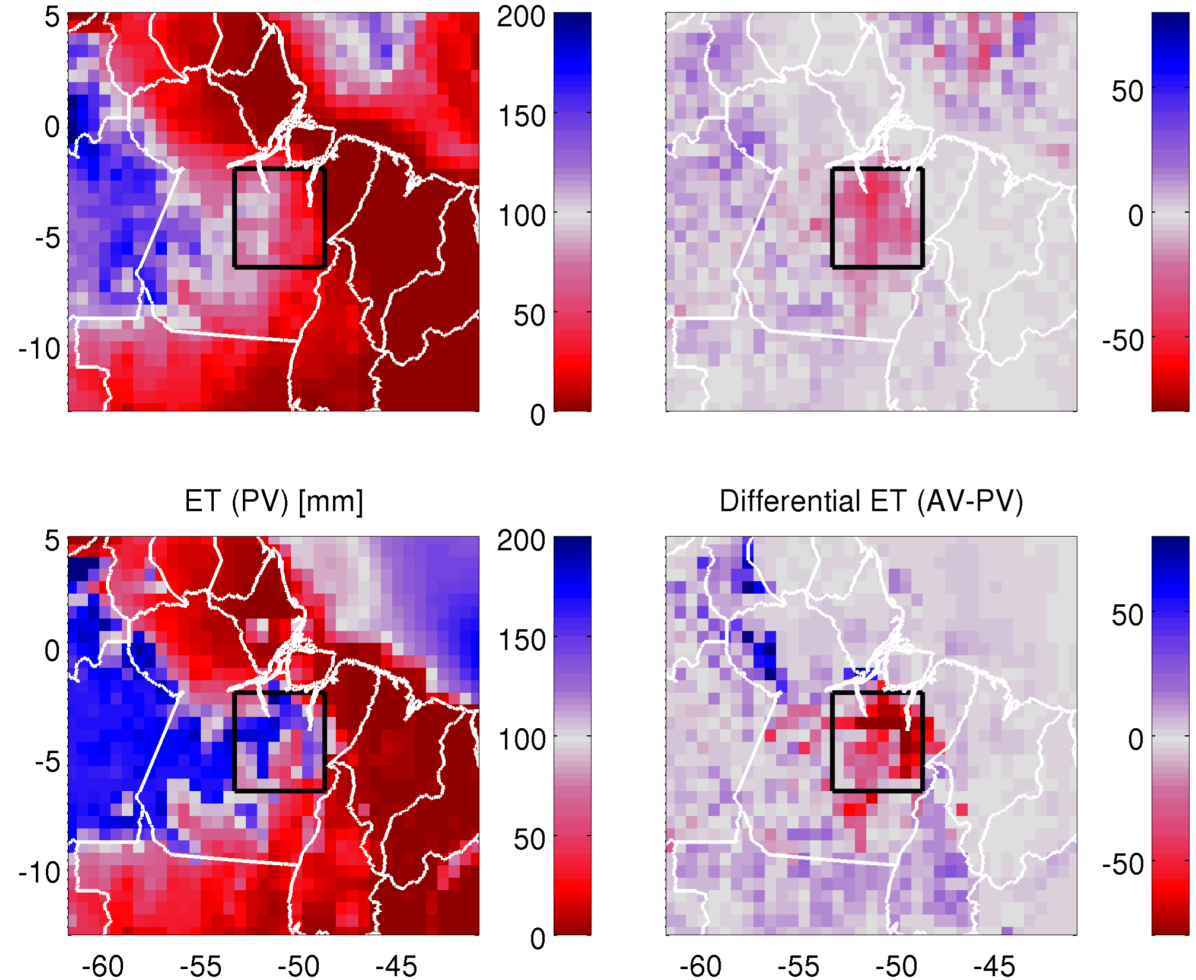

Figure 11. Monthly integrated surface water fluxes over the Pará focus region, September 2003. Upper left panel: map of integrated monthly precipitation for the potential vegetation simulation (PV). Upper right panel: map of the integrated difference in monthly precipitation, actual vegetation case minus the potential vegetation case (AV-PV). Lower left panel: map of integrated monthly evapotranspiration for the potential vegetation simulation. Lower right panel: map of the integrated difference in monthly evapotranspiration, actual vegetation case minus the potential vegetation case. 

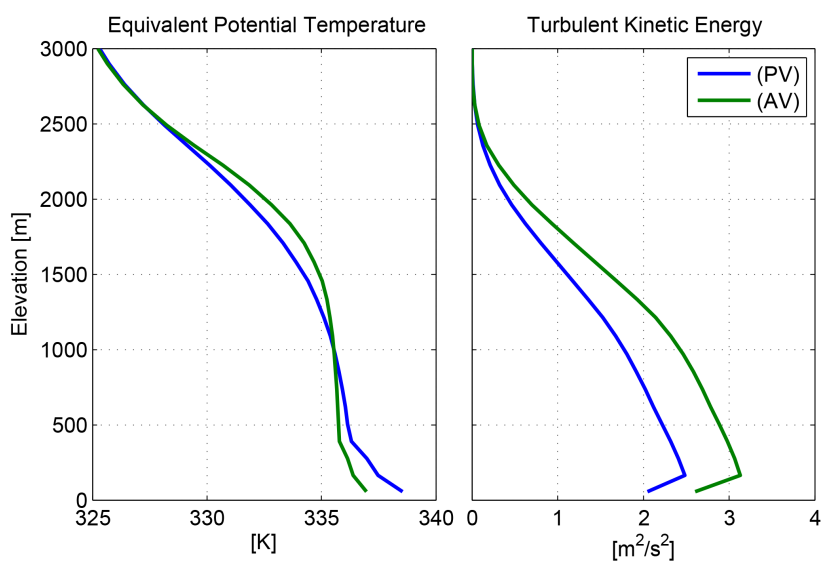

Figure 12. Mean profiles of Equivalent Potential Temperature and Turbulent Kinetic Energy at $15 \mathrm{Z}$ within the bounded domain at Pará, September 2003.

uitously associated with regional increases in runoff. In a regional water balance analysis, d'Almeida et al. (2007) also observed that wide-spread regional deforestation promoted decreased evapotranspiration and increased runoff. Similar to this study, they also found that precipitation feedback response to deforestation had the potential to impact the water cycling on par with direct effects of surface hydrologic parameters (although in their results, bi-directionally weakening or strengthening the water cycle depending on heterogeneity and land-cover fractionation).

In the simulations presented here, the increased continental runoff from the actual scenario is driven by higher mean annual soil moisture. The regional mean soil moisture depth simulated in the actual scenario oscillated around a interseasonal mean of $1.40 \mathrm{~m}$ (over an $8 \mathrm{~m}$ medium), averaging $5 \mathrm{~cm}$ greater than the potential case. As increased runoff has a negative feedback on increased soil water, and there was no consistent bias in precipitation, it is most likely that the positive shift in mean annual moisture in the actual scenario is driven by the decreases in regional evapotranspiration.

This experiment highlighted the use of relatively sophisticated vegetation biophysical processes, which incorporated variable vegetation structure, composition, rooting depth and uptake. However, the modeling framework did not incorporate lateral transport of any surface moisture. Therefore, these results must be interpreted with the understanding that lateral re-infiltration, lateral vadose-zone flow, interflow and water table dynamics could not influence soil moisture dynamics. In light of this, this experiment provides a gauge on the strength of the control that evaporation response to deforestation can have on regional water balance and runoff generation. There has been some evidence that soil hydrologic properties can be affected by land conversion in the tropics, Zimmermann et al. (2006) found that both infiltrability and upper root-zone saturated hydraulic conductivity was highest in intact rainforest compared to pasture and tree planta- tions. Decreased infiltration in pastures has been related to increased runoff generation as well (Muñoz-Villers and McDonnell, 2013). But there seems less certainty in the literature in quantifying the evaporative response from canopy and soil to regional Amazonian deforestation, degradation and recovery.

\subsection{Intersection of seasonal hydrology and represented plant functional types on canopy process}

The two case studies showed that the structure of the vegetation canopy can influence the seasonal cycle of moisture storage and land-atmosphere moisture flux. At the Gran Chaco site, transpiration was greater in the potential vegetation scenario during the wet season when the deeper roots and higher stomatal density of the open canopy forest could access available soil moisture. Alternatively, total evapotranspiration was greater in the actual vegetation scenario at the onset of the dry-season, mostly due to the fact that the grasslands had more available water stored in the upper root zone (recall Fig. 10).

The natural vegetation at the Gran Chaco site is represented "in model" with early successional broadleaf evergreen plant functional types, with accompanying $\mathrm{C} 4$ grasses. While the demographic size structure, composition, and the openness of the canopy shows some similarity with dryforest structure, it must be realized that the wider range of water conservation strategies observed in nature could influence how the differences in surface-to-atmosphere energy fluxes play out at this site.

These findings suggest that the next generations of earth system models may benefit from improvements in representing plant diversity. The seasonal flux of surface-toatmosphere water vapor is regulated by plants, and can potentially impact the hydrometeorological dynamic of the region. Total evapotranspiration during the transition from the late wet season to early dry season (April) at the Gran Chaco site was larger in the potential vegetation scenario. As shown in the hydrometeorological analysis in Sect. 4.4, this was a time in the seasonal cycle that exhibited relatively strong differences in the instability profiles in the atmosphere, albeit from competing local and regionally driven mechanisms.

\subsection{Drivers of anomalous convective precipitation}

The negative precipitation bias at the two focus areas in the actual scenario were both accompanied by reductions in net radiation, decreased annual latent heat flux (evapotranspiration) and increased albedo. They also experienced boundary layers with lower mean equivalent potential temperature, which was then related to fewer cumulus events that lacked sufficient convective available potential energy to generate deep clouds (diagnosed through convective logs). It is believed that differences in convective available potential energy underlies the convective precipitation anomaly. 

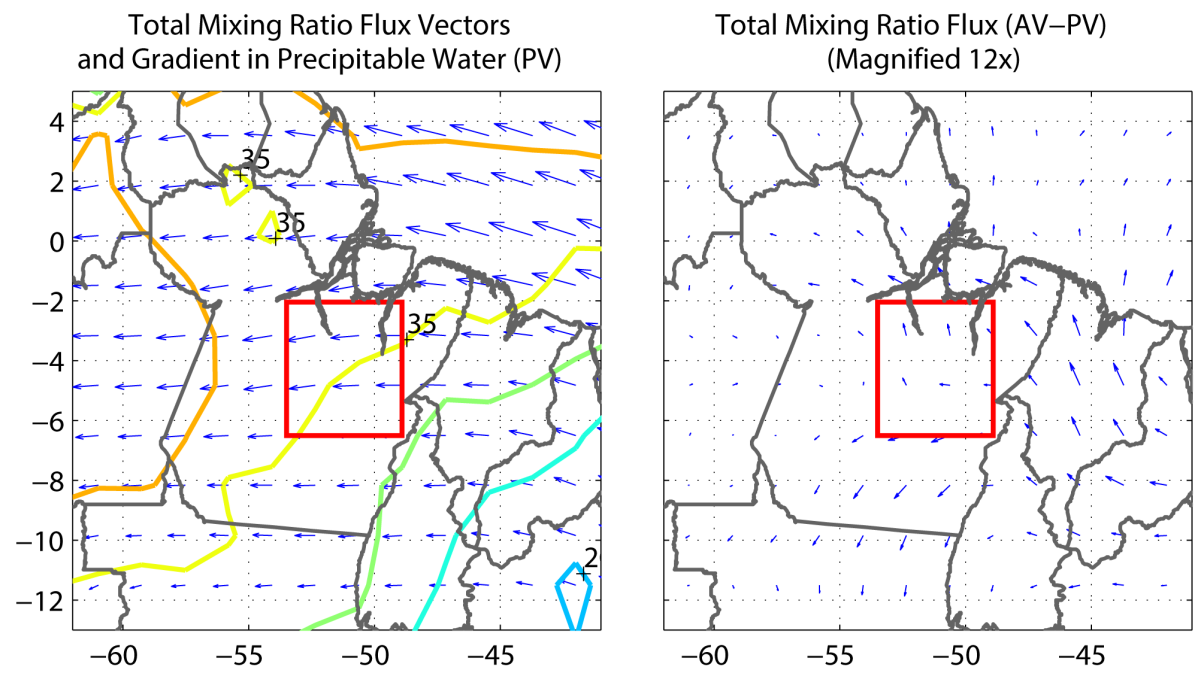

Figure 13. Left panel: map of vertically integrated total water advective flux vectors (quivers) and vertically integrated precipitable water (contours) for the potential vegetation case (PV), region near the Pará site, September 2003. Quivers are scaled and convey only directionality and relative magnitude. Contours of low precipitable water are shown by cool colors (blues) and high precipitable water with warm colors (reds). Right panel: the differential in vertically integrated advection of total precipitable water, actual vegetation minus potential vegetation (AV-PV). Quivers are scaled to 12 times relative to the left panel. In both panels the sub-domain bounding the Pará focus region is shown with a red box.
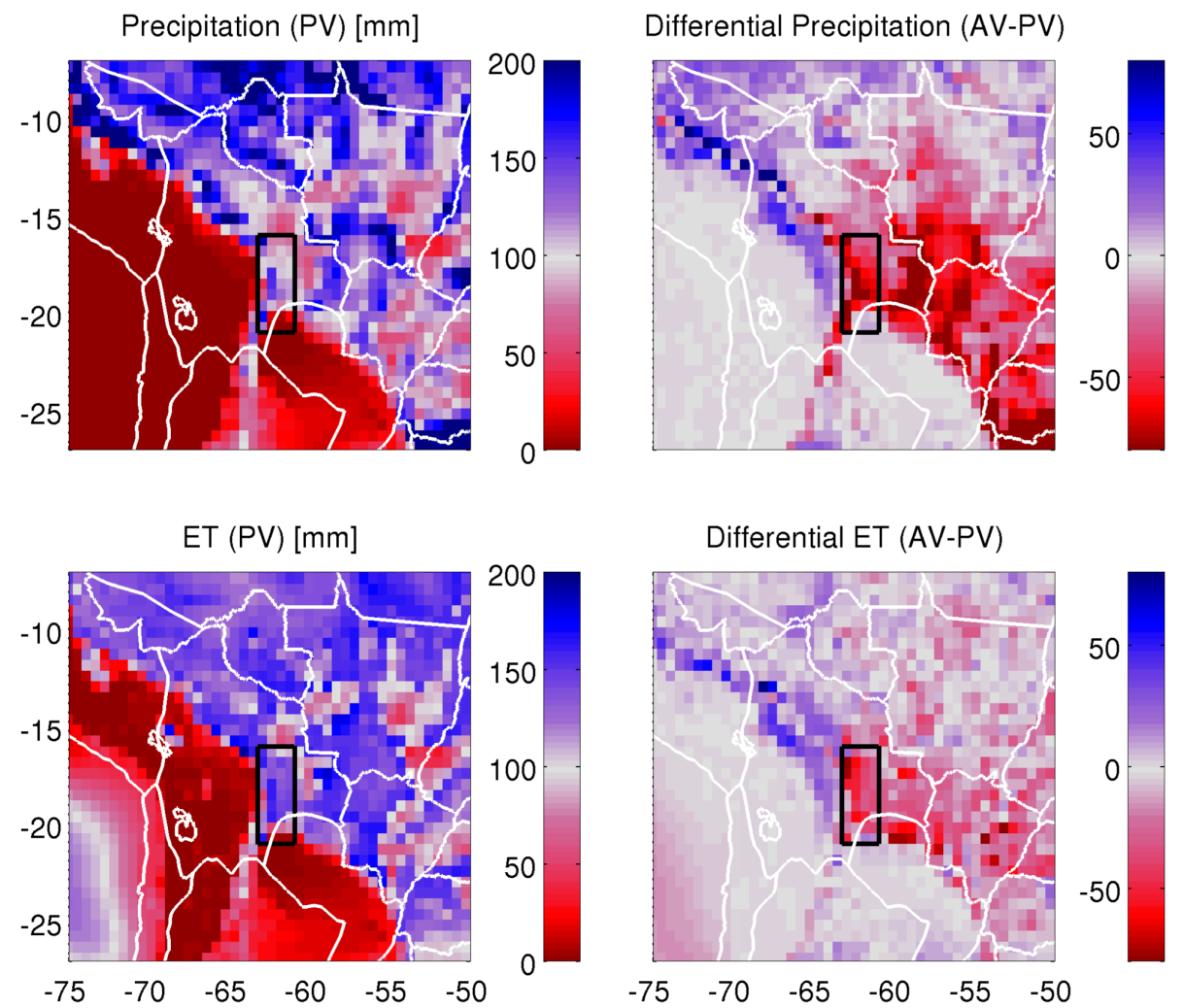

Figure 14. Monthly integrated surface water fluxes over the Gran Chaco focus region, April 2003. Upper left panel: map of integrated monthly precipitation for the potential vegetation simulation (PV). Upper right panel: map of the integrated difference in monthly precipitation, Actual vegetation case minus the potential vegetation case (AV-PV). Lower left panel: map of integrated monthly evapotranspiration for the potential vegetation simulation. Lower right panel: map of the integrated difference in monthly evapotranspiration, actual vegetation case minus the potential vegetation case. 

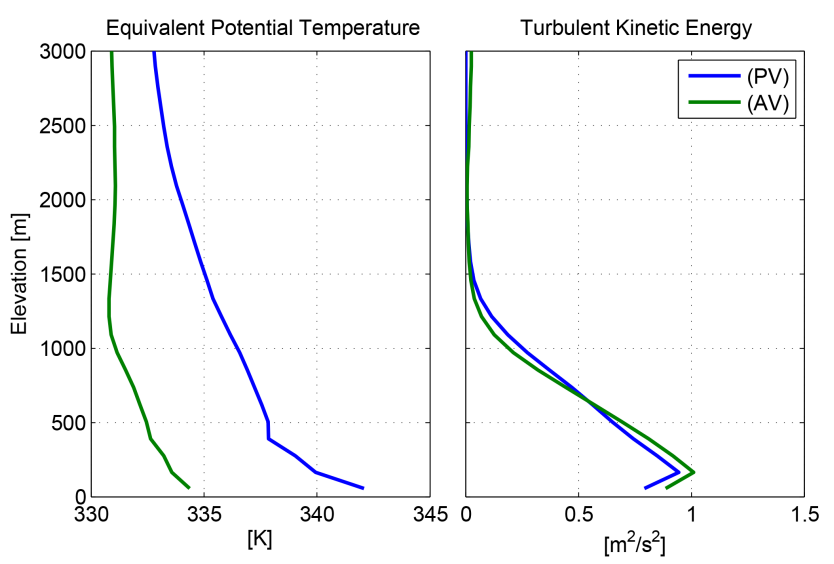

Figure 15. Mean profiles of equivalent potential temperature and turbulent kinetic energy at $15 \mathrm{Z}$ within the bounded domain at Gran Chaco, April 2003.

Positive anomalies in sensible heat flux for the actual scenario are concurrent with increased turbulent kinetic energy, which is thought to promote the circulations and boundary layer development that lifts air parcels to trigger convection (Wang et al., 2009; Fisch et al., 2004). The case study at Pará did show increased boundary layer turbulent kinetic energy and sensible heat flux, and it is possible that increased boundary layer turbulence may have helped recoup some losses in precipitation. This is deductive reasoning; however, following that the Gran Chaco case study did not have increased turbulent kinetic energy associated with the actual scenario and it did experience more failed convective events associated with the inability to overcome convective inhibition (where there was no such trend at Pará).

The two case studies offer evidence that the negative precipitation anomaly, can be mediated by by primarily local effects and also by a combination of local effects and regional circulation effects. The Pará case study suggests that the negative precipitation anomaly is driven primarily by changes in the local surface energy flux. The dry season prevailing winds at Pará flowed up the moisture gradient (i.e., gaining moisture, not losing moisture). And according to the flux vectors in Fig. 13, despite the decreased precipitation experienced in the actual scenario, the prevailing winds fluxed more moisture into the domain when compared to the potential case. In contrast, the Gran Chaco case study showed evidence that the precipitation anomaly was responding to a change in the regional circulation as well as changes in the local surface energy fluxes. Here, the prevailing winds came out of the north and flowed down the moisture gradient (i.e., losing moisture). While the domain was a net source of moisture (divergent) the net flux into the domain via advection was positive. The actual scenario experienced a relative decrease in advected moisture flux from the prevailing winds (see Fig. 16).

\subsection{Uncertainty in model estimates}

Estimation uncertainty in coupled regional models exist in many sources, including the initial condition, the boundary conditions, the scale limitations of the resolved processes, the mechanics of the model processes and the parameters that govern the processes. In limited area models, there is also variability in the lateral boundary conditions. For the current research, this variability can affect the differences detected between the two scenarios, potentially impacting results. Ideally, this variability space can be explored in depth, perhaps using ensembles over multiple decades, including differing starting years and perturbations. The range of the variability space that can be sampled is limited by computational expense of the simulations. The 4-7 year simulations presented here took approximately 2 months each using 96 parallel computational cores with high-speed interconnects, the computational time being an result of the highly memory intensive ecosystem model and atmospheric time stepping that is relatively short (30 s) compared to general circulation models. However, we maintain that the the pattern differences in precipitation and evaporation between the two scenarios showed consistency enough to merit commentary.

The simulations used a number of different external data sets, each of which contained information at different spatial scales. This includes the soils information (variable scales), the human disturbance transitions $\left(1^{\circ}\right)$, the scale at which the forest structure was "spun-up" from climate driver data $\left(1^{\circ}\right)$ versus the scale at which that data was re-sampled (using nearest neighbor) in the coupled simulation $(64 \mathrm{~km})$. The uncertainty associated with the dynamics of the coupled simulations are subject to the scale of the information provided by these external data sets, as well as any biases that might be inherent in those data sets. This may be particularly true in the case of the lateral boundary condition data.

It is also necessary to acknowledge that there is uncertainty inherent in model process. For instance, in the absence of explicitly resolving buoyant updrafts (which is not possible in mesoscale simulations), the successful triggering of convection was based on the negative energy between the level of updraft and the level of free convection. There are alternative methods for estimating where updrafts start and how a parcel may or may not overcome inhibition to reach free buoyancy. We chose a straight forward parameterization that compares the negative buoyancy to a threshold. There are other trigger mechanisms that can be used, such as estimating the statistical distribution of vertical kinetic energy present in eddy motions at the level of updraft, and using that to estimating the likelihood that eddies will overcome negative buoyancy through force balance computations. This is simply an example of how the simulations were undoubtedly influenced by these choices, and this is something that must be considered when interpreting the output from any complex numerical model. 

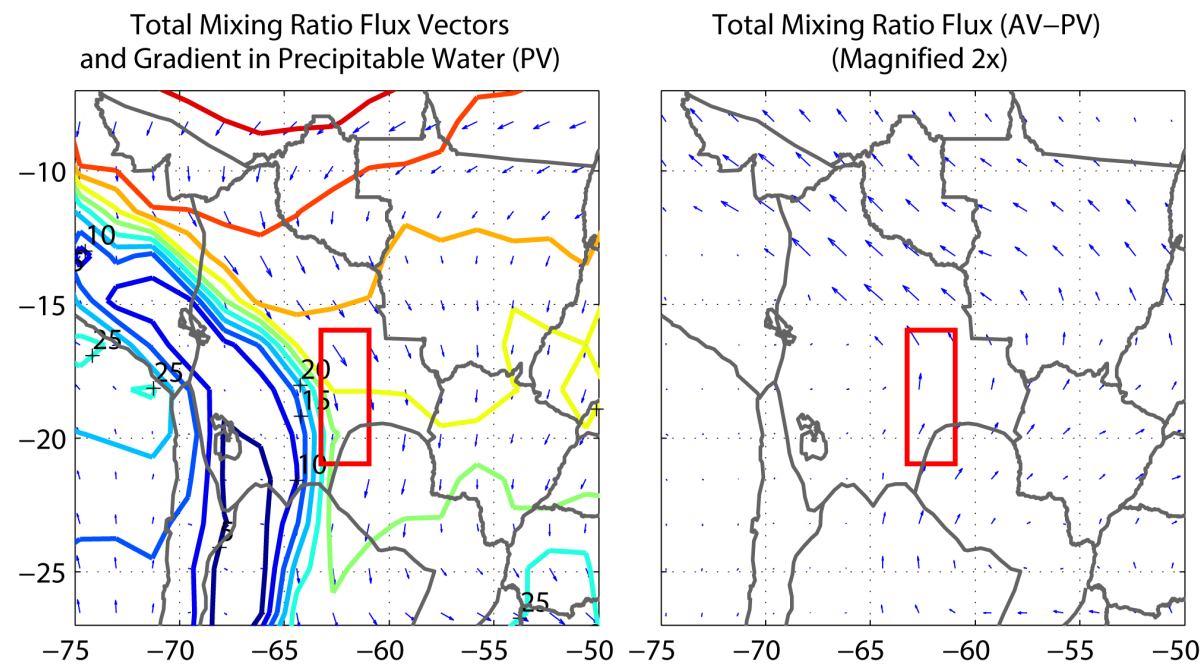

Figure 16. Left panel: map of vertically integrated total water advective flux vectors (quivers) and vertically integrated precipitable water (contours) for the potential vegetation case (PV), region near the Gran Chaco site, April 2003. Quivers are scaled and convey only directionality and relative magnitude. Contours of low precipitable water are shown by cool colors (blues) and high precipitable water with warm colors (reds). Right panel: the differential in vertically integrated advection of total precipitable water, actual vegetation minus potential vegetation (AV-PV). Quivers are scaled to 2 times relative to the left panel. In both panels the sub-domain bounding the Gran Chaco focus region is shown with a red box.

In the acknowledging uncertainty inherent in the simulations presented here, we have also tried to verify if these simulations can show agreement with observations. The actual scenario's simulations were compared to a group of different observations with the intention of verifying the modeling system's ability to represent key processes. The model's regional demographic of vegetation biomass was compared to field inventory data, atmospheric thermodynamic profiles were compared to soundings, mean all-sky profiles of cloud water were compared to satellite estimates and the seasonality of precipitation, net radiation, latent heat flux and sensible heat flux were compared with multi-data composite data products (see Appendices B-F). The comparisons with observations (which harbor their own uncertainty) suggest the model system is adequate to make a meaningful comparison between the two scenarios, yet not without room for improvement. In particular, this modeling study (and regional coupled simulations in general) would stand to benefit from improvements in how large-scale precipitation (weak spatiotemporal variability compared to point scale measurements) and canopy interception is handled.

A small selection of published research has conducted similar simulations to those reported here, with results that offer limited comparison. Perhaps most similar, Bagley et al. (2014) compared different land-cover scenarios with some similarities to our potential and actual vegetation, finding a generally weaker patterning of precipitation anomaly. However, evidence of the strongest pattern differences also occurred south of the Amazon delta, which may be viewed as correlated with the depression in the precipitation dipole pre- sented in this work. The simulations conducted by Bagley et al. (2014) also used a different modeling system (The Weather Research and Forecasting System WRF) and landsurface model (Noah LSM), suggesting that model intercomparison would be a useful endeavor in rectifying the regional hydrometeorological effects of South American land-cover change.

Other studies have used similar simulation approaches to the work described here, but targeted land-atmosphere effects under future conditions. Global simulations conducted by Medvigy et al. (2011) found that future business as usual (aggressive) deforestation would generate dipole precipitation differential with respect to conservative deforestation scenarios. The length scales of the patterning in the dipoles (100s of kilometers) showed similarity with results presented here. However, the locations of differences they presented were different, as of course were the driving land-use scenarios as well. Walker et al. (2009) also evaluated the effects of future deforestation scenarios on the regional hydrometeorology, finding that massive deforestation outside of protected areas will lead to basin-wide changes in rainfall, both positive and negative. In summary, there are some commonalities between the various regional simulations, albeit from differing land-use scenarios; impacts on hydrometeorological climate are expressed most strongly as changes in dry-season precipitation, and that patterning exists to varying degrees at large length scales (>100 km) (Walker et al., 2009; Bagley et al., 2014; Medvigy et al., 2011). 


\section{Conclusions}

The simulations presented here produced negative anomalies in evapotranspiration rates that showed pattern similarity with areas where deforestation had driven noticeable differences in aboveground biomass. The results showed mixed support that historical land conversion has had influence on the patterning of South American precipitation. Over 4 years of simulation most of the region showed little consistency in annual anomalies. However, patterns in the precipitation anomaly emerged at specific locations, where mean annual precipitation showed moderate yet consistent differences as evaluated through a standard score. One pattern showed a dipole structure that occurred near eastern Pará Brazil. The other pattern, showed a negative anomaly in the Gran Chaco region of central and southern Bolivia. In this area, their was positive precipitation anomaly at the Peruvian-Bolivian border, yet the general patterning may not-necessarily be considered a dipole.

The simulations suggest land conversion in South America has not had a large impact on mean precipitation in the region as a whole. Mean regional precipitation was lower in the $a c$ tual scenario in only 3 of the 4 simulation years. In contrast, differences in mean continental runoff (increased with human land conversion) and total evapotranspiration (decreased with human land conversion) were both consistent from year to year and showed greater differences compared to precipitation.

It was also observed that a large-scale shift in forest composition to early successional tropical evergreens following deforestation and abandonment in central eastern Amazon produced a noticeable increase in grid-average transpiration. This increase was striking not only because the pattern difference matched the pattern shift in composition, but particularly because the overall biomass in this area had decreased compared to the natural (potential) condition, suggesting that the physiological differences of the vegetation had influenced regional fluxes and not necessarily the quantity.
Beyond characterizing mean and pattern differences in the regional water balance, it was identified that changes (be they moderate) in precipitation may have occurred in locations where terrestrial vegetation actively regulates photosynthesis due to water limitations and that the changes in precipitation can be attributed to combinations of changes in local surface fluxes and changes in the regional atmospheric circulation. An assessment of the regional vegetation's response to moisture stress has indicated that both these locations show some susceptibility to changes in root-zone soil moisture (plant stomata were actively regulated to conserve water over a broad range depending on exact location, varying from $20-80 \%$ of the time); however, the ecosystems of Gran Chaco are generally dryer and show greater susceptibility.

In both focus cases, deforestation led to increases in total surface albedo, driving decreases in net radiation, boundary layer moist static energy and ultimately convective precipitation. However, the differences in precipitation at Pará Brazil are more strongly connected with these localized differences in land-surface energy flux. The hydrometeorological analysis near Gran Chaco suggests that human land-conversion has had some impact on the strength of the South American moisture circulation in the southwestern portion of the Amazon, which claims partial responsibility along with differences in surface fluxes for an estimated decrease in annual precipitation in the Gran Chaco. 


\section{Appendix A: Land-atmosphere model coupling}

The atmospheric model (BRAMS) and the land surface model (ED2) are loosely and asynchronously coupled. This assumes that the two models pass each others' boundary conditions at a frequency that captures the natural variability of the flux, yet the fluxes between models are not dynamically changing as prognostic variables within the numerical integrator sub-stepping. The atmosphere (BRAMS) provides information at the beginning of the ED2 forward step, while ED2 assumes this information is constant over the duration of its forward step and makes a time average of the fluxes during the step to return.

Mesoscale atmospheric models at spatial resolutions of tens of kilometers typically perform integrations on the order of tens of seconds to maintain numerical stability and convergence. The simulations in this work used an atmospheric time step of $30 \mathrm{~s}$ (for non-acoustic dynamics, acoustics were 10 s). Ideally, the land surface and atmospheric models operate at time steps that approach the infinitesimally small. The ED2 has a non-trivial computational overhead due to the large number of vegetation cohorts experiencing energy balancing within each grid cell. Ultimately, the ED2.1 model used a $120 \mathrm{~s}$ time step while coupled to BRAMS.

Atmospheric variables such as air temperature, humidity and wind-speed are provided to ED2 at a reference height of $70 \mathrm{~m}$. This is required because ED2 internally calculates turbulent transport of heat, moisture and momentum through the canopy and into the inertial sub-layer of the lower atmosphere. The turbulent transport of scalars through the sublayer above the canopy were calculated following Beljaars and Holtslag (1991). These calculations relied on gradients that were based on the enthalpy, density and specific humidity of air at reference temperature and within the canopy's interstitial air-space. A list of the variables required to drive $\mathrm{ED} 2$ is provided in Table A1.
The ED2 model passes boundary fluxes at the grid scale to the atmospheric surface layer as an area-weighted average across patches. There are three groups of information the land surface must provide the atmosphere model: (1) the topography which governs the geometry of the atmosphere's coordinate system and drag, (2) a lower boundary condition for turbulent closure, i.e., the vertical velocity perturbations of momentum, heat, moisture and carbon, and (3) a surface albedo for the atmospheric radiative transfer calculations. These variables are listed in Table A2. Because the ED2 model prognoses spatial variables at the patch sale (such as canopy temperature, humidity, etc), spatial averaging is required for flux variables. For any generic variable $S$, at a grid cell with $M$ patches of area $A_{\text {patch }}$, the area averaged quantity is straight forward.

$$
\begin{aligned}
& S_{\text {grid }}=\sum_{j}^{M} S_{\text {patch }, j} A_{\text {patch }, j} \\
& \sum_{j}^{M} A_{\text {patch }, j}=1
\end{aligned}
$$

More detailed explanation of how turbulent fluxes are calculated in the ED2 model can be found in Medvigy et al. (2009) and Knox (2012). 
Table A1. Atmospheric boundary conditions provided by BRAMS, that drive the ED2 model.

\begin{tabular}{lll}
\hline Symbol & Units & Description \\
\hline$u_{x}$ & {$\left[\mathrm{~m} \mathrm{~s}^{-1}\right]$} & Zonal wind speed \\
$u_{y}$ & {$\left[\mathrm{~m} \mathrm{~s}^{-1}\right]$} & Meridional wind speed \\
$T_{\mathrm{a}}$ & {$[\mathrm{K}]$} & Air temperature \\
$q_{\mathrm{a}}$ & {$\left[\mathrm{kg} \mathrm{kg}^{-1}\right]$} & Air specific humidity \\
$\dot{m}_{\mathrm{pcp}}$ & {$\left[\mathrm{kg} \mathrm{s}^{-1}\right]$} & Precipitation mass rate \\
$z_{\mathrm{ref}}$ & {$[\mathrm{m}]$} & Height of the reference point \\
$R_{\mathrm{ld}}$ & {$\left[\mathrm{w} \mathrm{m}^{-2}\right]$} & Downward longwave radiation \\
$R_{\mathrm{vb}}$ & {$\left[\mathrm{w} \mathrm{m}^{-2}\right]$} & Downward shortwave radiation, visible beam \\
$R_{\mathrm{vd}}$ & {$\left[\mathrm{w} \mathrm{m}^{-2}\right]$} & Downward shortwave radiation, visible diffuse \\
$R_{\mathrm{nb}}$ & {$\left[\mathrm{w} \mathrm{m}^{-2}\right]$} & Downward shortwave radiation, near infrared beam \\
$R_{\mathrm{nd}}$ & {$\left[\mathrm{w} \mathrm{m}^{-2}\right]$} & Downward shortwave radiation, near infrared diffuse \\
\hline
\end{tabular}

Table A2. ED2 flux variables providing the lower boundary condition for the BRAMS atmospheric model.

\begin{tabular}{lll}
\hline Symbol & Units & Description \\
\hline$\overline{\left(u^{\prime} w^{\prime}\right)}$ & {$\left[\mathrm{m}^{2} \mathrm{~s}^{-2}\right]$} & Average vertical flux of horizontal wind velocity perturbations \\
$\overline{\left(w^{\prime} w^{\prime}\right)}$ & {$\left[\mathrm{m}^{2} \mathrm{~s}^{-2}\right]$} & Average vertical flux of vertical wind velocity perturbations \\
$\overline{\left(t^{\prime} w^{\prime}\right)}$ & {$\left[\mathrm{mK} \mathrm{s}^{-2}\right]$} & Average vertical flux of temperature perturbations \\
$\frac{\left(q^{\prime} w^{\prime}\right)}{\left(c^{\prime} w^{\prime}\right)}$ & {$\left[\mathrm{kg} \mathrm{m}^{-2} \mathrm{~s}^{-2}\right]$} & Average vertical flux of moisture perturbations \\
$\chi_{\mathrm{s}}$ & {$\left[\mu \mathrm{mol} \mathrm{m}^{-2} \mathrm{~s}^{-2}\right]$} & Average vertical flux of carbon perturbations \\
$\chi_{1}$ & {$[-]$} & Average total shortwave albedo \\
$R_{\mathrm{lu}}$ & {$\left[\mathrm{w} \mathrm{m}^{-2}\right]$} & Average total longwave albedo \\
\hline
\end{tabular}




\section{Appendix B: Regional above-ground biomass}

The model estimated live above-ground biomass (AGB) and basal area (BA) that represent the initial condition is compared with a collection of census measurements in Baker et al. (2004a, b) (see Fig. B1). A map is provided showing the locations of the plot experiments (see Fig. B2). The coordinates from the measurement stations were matched with ED2 nearest neighbor grid cells. Consistent with observations, only ED2 plants greater than $10 \mathrm{~cm}$ in primary forests were included in the comparison. The published measurements were taken at different times over the previous decades, the lag between these sites and the time of the simulation initial condition (January 2008) varies and is reported. Tree diameters in ED2 is diagnosed allometrically from structural carbon, similar to allometric equations in Chave et al. (2001) and Baker et al. (2004b), with differences in parameterization to reflect functional groups.

Please note that the forest inventory data makes no assumption that aboveground biomass is in equilibrium. This comparison is only intended to evaluate the present day static representation of forest structure. As applied to the coupled simulation, the were treated as static. As stated earlier, the length of the simulation did not merit the need to incorporate dynamics.
The majority of sites show fair agreement with model estimated above-ground biomass and basal area. The exception to this is the cluster of sites located in eastern Bolivia at Huanchaca Dos (HCC), Chore 1 (CHO), Los Fierros Bosque (LFB) and Cerro Pelao (CRP). There are several potential reasons for this discrepancy attributed to the model such as: variability in (1) climate forcing data (most notably precipitation and vapor pressure deficit as these are water limited growth conditions), (2) edaphic conditions and (3) plant functional parameters. These plots are close to the southern Amazonian transition between tropical rain-forests and Cerrado type open canopy forests where gradients in vegetation types are large and uncertainty is expected to be greater. Large spatial gradients in biomass are also reflected in the differences among the cluster of plots (HCC, CHO, LFB and CRP), (124.8 $\mathrm{Mg} \mathrm{ha}^{-1}$ above-ground biomass at $\mathrm{CHO}$ and $260.0 \mathrm{Mg} \mathrm{ha}^{-1}$ AGB at HCC). The sharp gradient in forest biomass suggests that the omission of sub-pixel variability in the modified DS314 climate forcing could explain a portion of this difference, along with any persistent biases. 

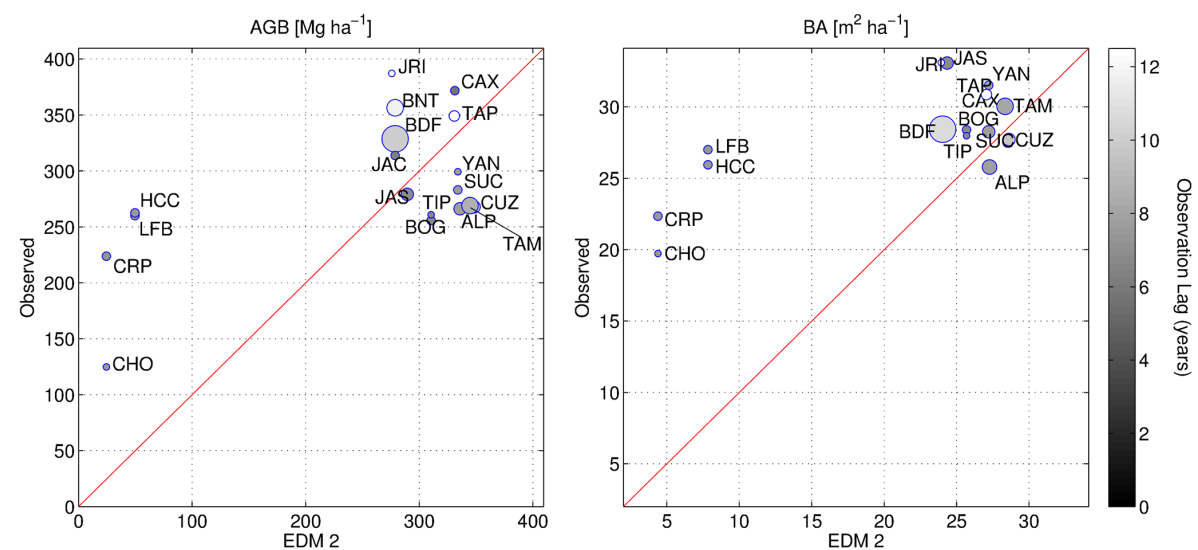

Figure B1. Comparison of model estimated mean above-ground biomass (AGB) and basal area (BA) with measurements presented in Baker et al. (2004a, b). Circle size shows relative approximation of the number of census sites used in the field measurements reported in Baker - maximum $=11$ separate plots at BDF (code for the Biological Dynamics Forest Fragments Project). Darker circles indicate that measurements were taken more recently and therefore have less time lag in the comparison with the ED2 initial condition (January 2008). In accord with methods of Baker et al. (2004a, b), model estimates were filtered to include only primary forests and ignored vegetation less than $10 \mathrm{~cm}$ diameter. Coarse woody debris was excluded from comparison, only live stems were accounted for.

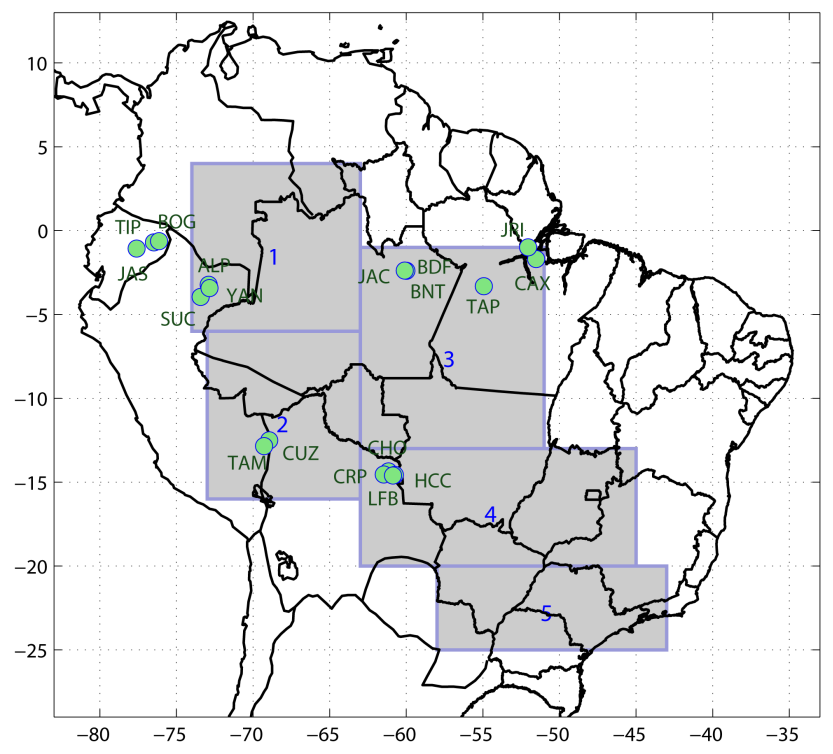

Figure B2. Locations of zones and sites of analysis. Zones are numbered 1 through 5, and reflect geographic areas where model and observation spatial means are compared for validation (see Appendix D and E). Forest census plot sites from Baker et al. (2004a, b) are referenced with green markers and their station code. Station codes designate the following site names: Allpahuayo (ALP), BDFFP (BDF), Bionte (BNT), Bogi (BOG), Caxiuana (CAX), Chore (CHO), Cerro Pelao (CRP), Cuzco Amazonico (CUZ), Huanchaca Dos (HCC), Jacaranda (JAC), Jatun Sacha (JAS), Jari (JRI), Los Fierros Bosque (LFB), Sucusari (SUC), Tambopata (TAM), Tapajos (TAP), Tiputini (TIP) and Yanamono (YAM). 


\section{Appendix C: Thermodynamic mean profiles}

The objectives of this experiment require that modeling system output match mean observations to such a degree that there is trust in the model's ability to represent physical processes. It is believed that the relative differences between the two simulations have validity if model processes reproduce mean observed tendencies in the land surface and atmosphere.

Mean monthly profiles of model estimated air temperature, specific humidity and moist static energy are compared with mean radiosonde data over Manaus Brazil (see Figs. C1 and C2). Comparisons are made at 00:00 UTC (20:00 LT) and 12:00 UTC (20:00 LT). The model estimates a consistently warmer atmosphere, in the range of about two degrees both morning and evening. Model estimated specific humidity in the lower troposphere is lower than the radiosondes (see Fig. C1). Moist static energy is slightly underestimated by the model in the lower troposphere and then overestimated in the mid to upper troposphere. This may suggest that the model is convecting relatively large quantities of warm, moist air at the surface and entraining it to the upper atmosphere.
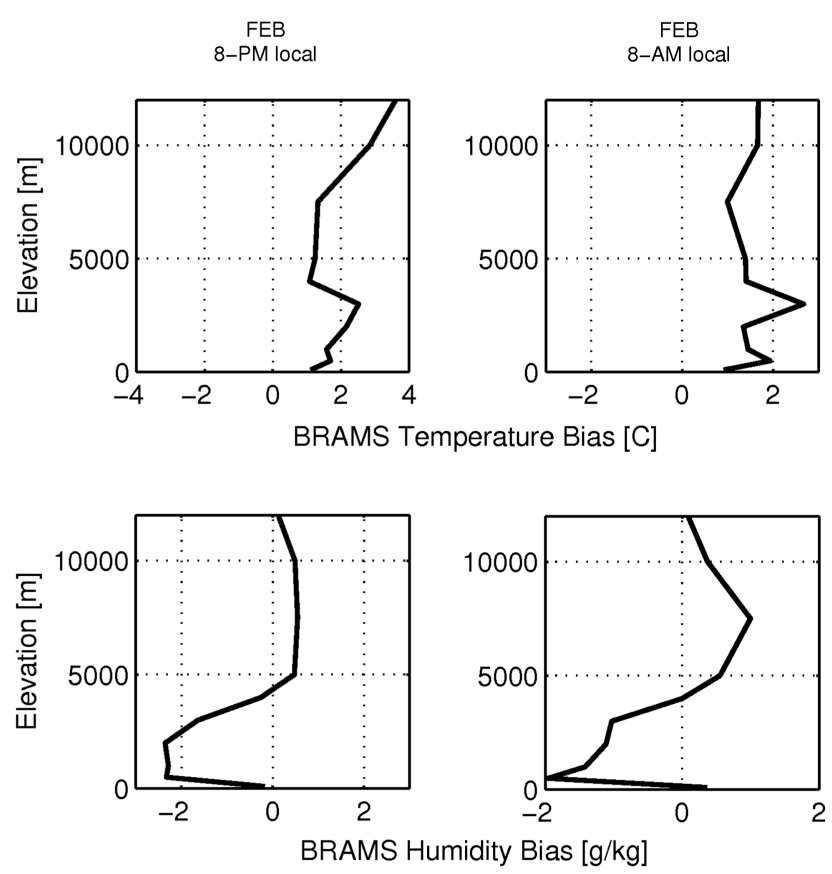

Figure C1. Comparison of model estimates with radiosonde data, differences in mean air temperature and specific humidity. Manaus, February 2003.
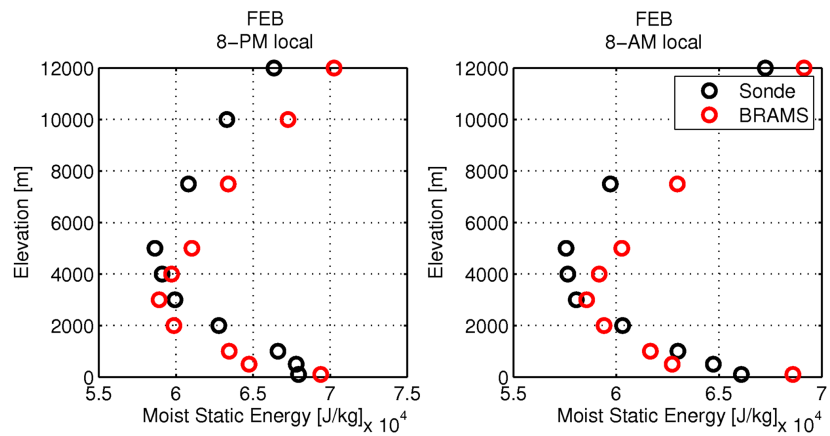

Figure C2. Comparison of model estimated mean moist static energy with rawinsonde measurements. Manaus, February 2003. 


\section{Appendix D: Inter-seasonal precipitation and surface radiation}

Monthly precipitation and downwelling shortwave radiation in the model is evaluated as spatial means within five separate zones of analysis. The boundaries of the zones of analysis are shown in Fig. B2. Monthly mean model estimates are again compared to precipitation estimates from the Tropical Rainfall Measurement Mission (TRMM) 3B43 product and surface radiation from the Global Energy and Water Exchanges Project (GEWEX) Surface Radiation Budget (SRB) product version $2.5^{3}$ There is generally acceptable agreement between the model and TRMM estimated precipitation. The seasonal variability in both data sets is greater than their differences (see Fig. D1). The largest differences are reflected in the strength of of the wet-season peak precipitation in Zone 3 (central eastern Amazon) and the severity of the dry season precipitation in Zone 5 (southern Brazil). The timing of peak and minimum rainfall show generally good agreement, particularly in Zones 2-5. The lower estimate of mean precipitation in southern Brazil is consistent with decreased cloud albedo and increased downwelling shortwave radiation at the surface (see Fig. D2). Surface shortwave radiation is modestly over-estimated compared with the SRB estimates for most other cases.

\footnotetext{
${ }^{3}$ These data were obtained from the NASA Langley Research Center Atmospheric Sciences Data Center NASA/GEWEX SRB Project.
}

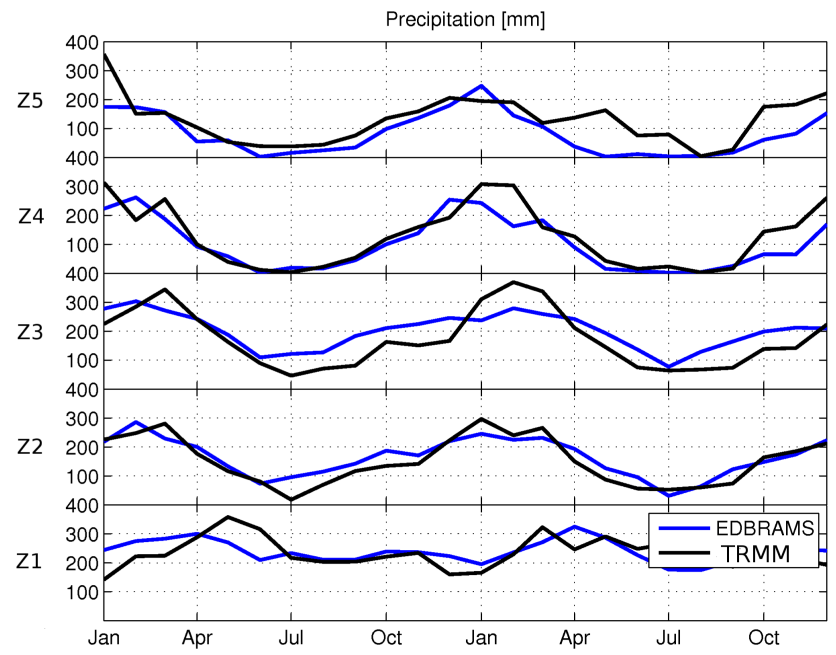

Figure D1. Mean monthly precipitation from ED2-BRAMS and the Tropical Rainfall Measurement Mission (TRMM) 3B43 product, years 2002-2003. Spatial means are taken within zones according to Fig. B2.

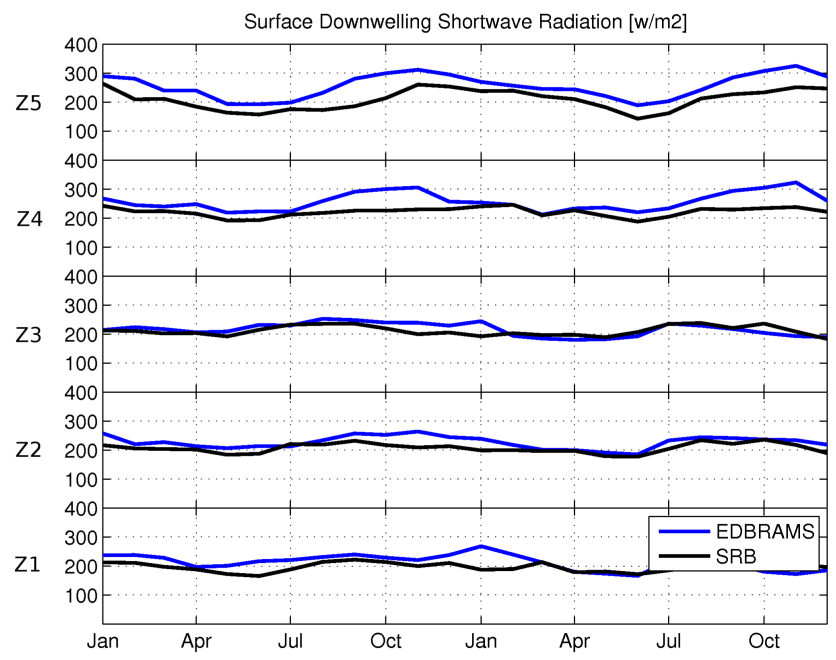

Figure D2. Mean monthly surface radiation from ED2-BRAMS and the Surface Radiation Budget (SRB) product version 2.5, years 2002-2003. Spatial means are taken within zones according to Fig. B2. 


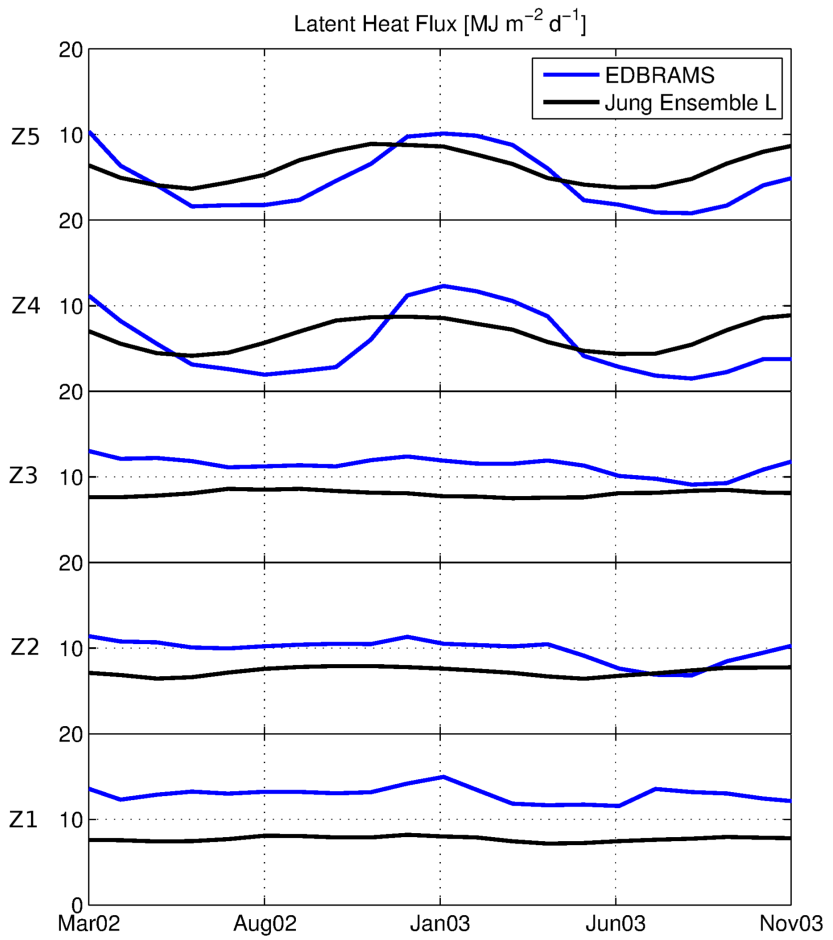

Figure E1. Mean monthly surface-to-atmosphere latent heat flux from ED2-BRAMS and the synthesis product from Jung et al. (2011, 2009). Spatial means are calculated over the zones shown in Fig. B2.

\section{Appendix E: Inter-seasonal latent and sensible heat flux}

Similar to the comparison in Appendix D, monthly mean model estimated latent (see Fig. E1) and sensible heat flux (see Fig. E2) are compared with means from a benchmark. In this case, we compare output with the products of Jung et al. (2011). These products are based off of surface observations, which are upscaled using gridded explanatory variables from various sources including the Climate Research Unit (CRU), Global Precipitation Climatology Centre (GPCC) as well as the ERA-Interim product used in this study. The interseasonal means also incorporate spatial means within the domains shown in Fig. B2.

The purpose of this comparison is to give some benchmark of the ecosystem model's ability to partition energy flux at the land surface. The patterned flux of energy is dependant on the atmospheric model and its lateral boundary conditions as well. Compared to the synthesis product, the model system estimated a stronger inter-seasonal variability of latent and sensible heat flux over southern Brazil and the South American Convergence zone. Both model and observations showed relatively lower seasonal variability over the Amazon. In these regions, the model estimated small biases in sensible heat flux.

The greatest discrepancies between benchmark and model output was a latent heat flux bias (higher in the EDBRAMS

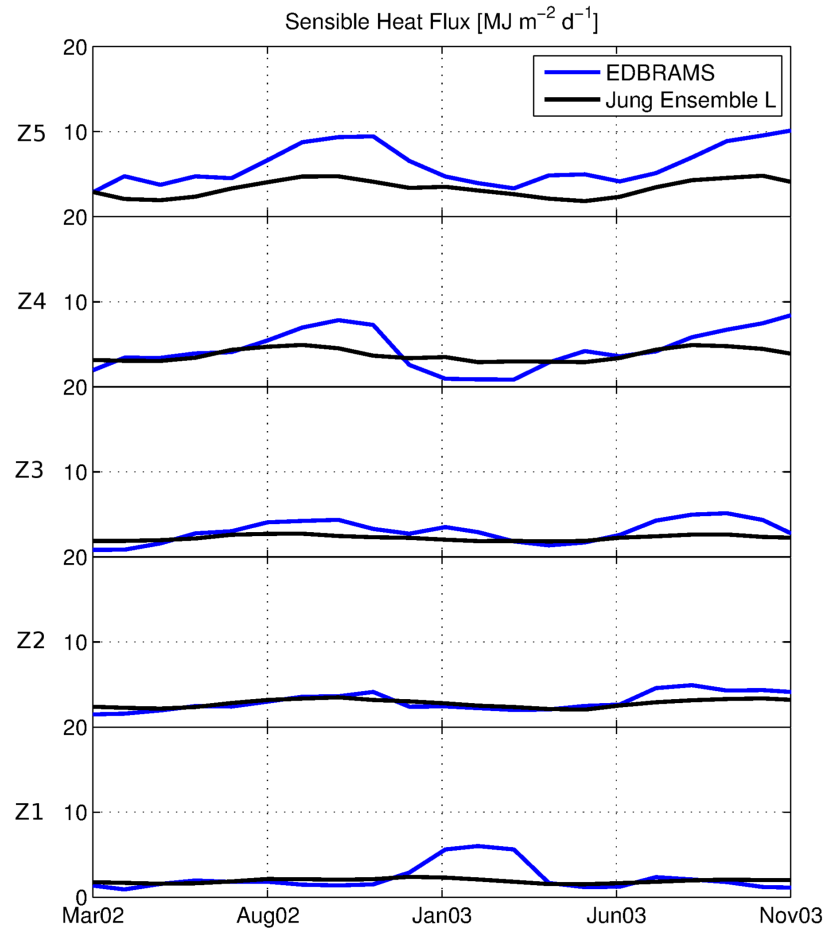

Figure E2. Mean monthly surface-to-atmosphere sensible heat flux from ED2-BRAMS and the synthesis product from Jung et al. (2011, 2009). Spatial means are calculated over the zones shown in Fig. B2.

model) among the three zones covering the Amazon Basin. There are several possible explanations for this, outside of uncertainty inherent in the benchmark product. Latent and sensible heat flux contribute a portion of the total energy flux balance through the land surface, which also includes contributions from change in storage, diffusive ground heat flux, net radiation and the enthalpy contained in the mass flux of precipitation and runoff (enthalpy flux from density and pressure changes can be assumed near zero). Latent heat flux also contributes to a portion of the water mass balance at the land surface, which also includes precipitation mass flux, change in storage and total runoff. During previous experiments with the ED2 model used in offline simulations, we found that the surface water balance was sensitive to the scale of the precipitation input. When driving the land-surface model with precipitation resolved at coarse scales (such as native NCEP and ECMWF products), the leaf evaporation rates were disproportionately high. It was found that low but continuous precipitation rates from these products promoted a slow wetting of canopy leaves, and as a result the canopy leaves overflowed to the point of generating throughfall with less frequency and magnitude. Point scale precipitation rates from rain gauges in the Amazon showed a much larger variability in precipitation intensity. After using downscaling routines based on Lammering and Dwyer (2000) to preserve the monthly volume of grid-cell precipitation and creating point- 
scale precipitation intensity, these products (specifically the DS314 from UCAR) elicited a shift in canopy throughfall rates thereby decreasing latent heat flux and increasing surface runoff. Precipitation scale and how it affects the distribution of intensity, storm duration and the time between storms is a challenge in couple model simulation, that cannot be overcome using the same techniques as offline simulations. The spatial and temporal resolution of the simulations used in this work ( $40 \mathrm{~km}$ with 15 min time step between convective precipitation calls) are smaller than the reanalysis models (larger than $1^{\circ}$ ), yet they cannot generate point-scale precipitation. There are various approaches to ameliorating precipitation scale effects, such as using multi-atmosphere multi-land (MAML) sub-grid methods and by employing creative ways at the land-surface to generate throughfall volumes that match observations even when driven with precipitation rates that cannot match those that are observed. Regional and mesoscale couple simulations such as the work presented here, could benefit greatly from advances in this area.

\section{Appendix F: All-sky cloud water content profiles}

Cloud profile validation data sets were constructed from CloudSat cloud water content (2B-CWC-RO) and cloud classification (2B-CLDCLASS-LIDAR) data sets. ${ }^{4}$ Overpasses during February 2007-2011 that intersected the geographic subset between $3^{\circ} \mathrm{N}-12^{\circ} \mathrm{S}$ and $70-55^{\circ} \mathrm{W}$ were collected and interpolated to a constant vertical datum above the surface. Overpasses typically occurred near 17:00 UTC.

Making a rigorous comparison of the model estimated cloud water and observation is challenging. Consider that the simulation time frame does not overlap with the CloudSat mission time frame, so these comparisons are treated as proxies to climatology and not weather validation. CloudSat measurements are known to have signal loss, attenuation and clutter during moderate to intense rainfall; events such as these could not be filtered from the comparison. It must also be assumed that the cloud classification algorithm is not without error. Nonetheless, the purpose of the comparison was to get a sense of whether the simulations estimated reasonable mean ranges of water contents and cloud fractions, and also if the phase transitions (liquid to ice) were occurring at reasonable elevations.
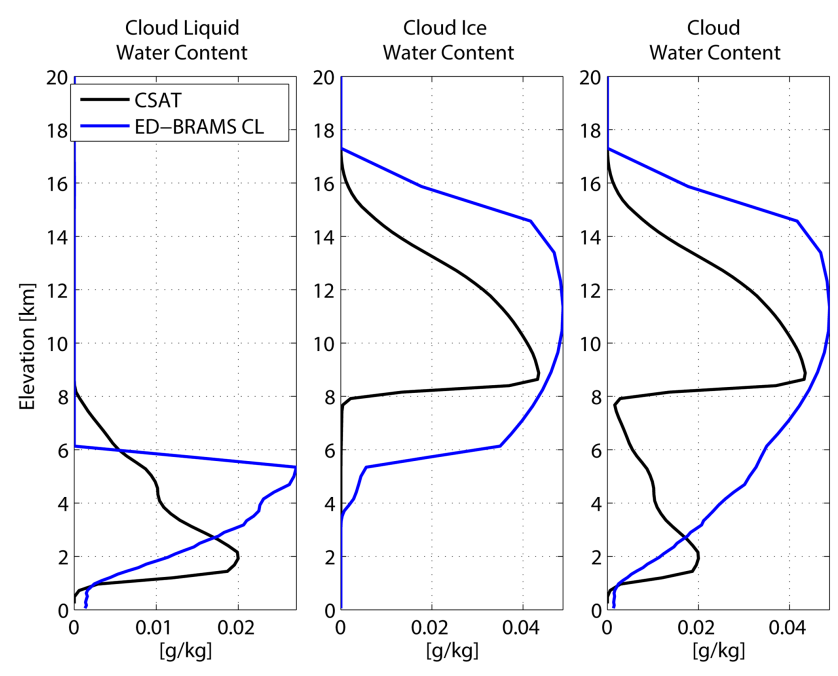

Figure F1. CloudSat climatological water content profiles and model estimated water content profiles for February 2003, 17:00 UTC, $3^{\circ} \mathrm{N}-12^{\circ} \mathrm{S}$ and $70-55^{\circ} \mathrm{W}$.

The all-sky cloud water content profiles for both cumulus and non-cumulus clouds are provided in Fig. F1. The peaks in model estimated mean cloud water content showed reasonable agreement across liquid and ice cloud types. The model estimated generally more water content in both phases, skewed towards higher altitudes and showed a unimodal shape in the vertical distribution. It is possible that CloudSat relative underestimation could be explained by the omission of precipitating clouds.

\footnotetext{
${ }^{4}$ CloudSat data sets were provided on-line by CloudSat Data Processing Center, courtesy of NASA, Colorado State University and their partners.
} 
Acknowledgements. This work was made possible through both the National Science Foundation Grant ATM-0449793 and National Aeronautics and Space Administration Grant NNG06GD63G. The authors would like to thank D. Entekhabi and E. A. B. Eltahir for their generous discussion and council. Further, the peer reviewers provided us with thorough, challenging and fair recommendations. We believe their efforts have contributed to significant improvements to this manuscript and we thank them.

Edited by: P. Regnier

\section{References}

Albani, M., Medvigy, D., Hurtt, G. C., and Moorcroft, P. R.: The contributions of land-use change, $\mathrm{CO}_{2}$ fertilization, and climate variability to the Eastern US carbon sink, Global Change Biol., 12, 2370-2390, 2006.

Anthes, R. A.: Enhancement of convective precipitation by mesoscale variations in vegetative covering in semiarid regions, J. Clim. Appl. Meteorol., 23, 541-554, 1984.

Asdak, C., Jarvis, P. G., van Gardingen, P., and Fraser, A.: Rainfall interception loss in unlogged and logged forest areas of Central Kalimantan, Indonesia, J. Hydrol., 206, 237-244, 1998.

Avissar, R. and Werth, D.: Global hydroclimatological teleconnections resulting from tropical deforestation, J. Hydrometeorol., 6, 134-146, 2005.

Bagley, J., Desai, A., Harding, K., Synder, P., and Foley, J.: Drought and deforestation: Has land cover change influenced recent precipitation extremes in the Amazon?, J. Climate, 27, 345-361, 2014

Baker, T., Phillips, O., Malhi, Y., Almeida, S., Arroyo, L., Fiore, A. D., Erwin, T., amd T.J. Killeen, N. H., Laurance, S., Laurance, W., Lewis, S., Monteagudo, A., Neill, D., Vargas, P., Pitman, N., Silva, N., and Vasquez-Martinez, R.: Increasing biomass in Amazonian forest plots, Philos. T. Roy. Soc. Lond. B, 359, 353-365, 2004a.

Baker, T., Phillips, O., Malhi, Y., Almeida, S., Arroyo, L., Fiore, A. D., Erwin, T., Killeen, S., Laurance, S., Laurance, W., Lewis, S., Lloyd, J., Monteagudo, A., Neill, D., Patino, S., Pitman, N., Silva, N., and Martinez, R. V.: Variation in wood density determines spatial patterns in Amazonian forest biomass, Global Change Biol., 10, 545-562, 2004b.

Baldi, M., Dalu, G. A., and Pielke, R. A.: Vertical velocities and available potential energy generated by landscape variability theory, J. Appl. Meteorol. Clim., 47, 397-410, 2008.

Beljaars, A. C. M. and Holtslag, A. A. M.: Flux Parameterization over Land Surfaces for Atmospheric Models, J. Appl. Meteorol., 30, 327-341, 1991.

Benegas, L., Ilstedt, U., Roupsard, O., Jones, J., and Malmer, A.: Effects of trees on infiltrability and preferential flow in two contrasting agroecosystems in Central America, Agr. Ecosyst. Environ., 183, 185-196, 2014.

Cardille, J. and Foley, J.: Agricultural Land-use Change in Brazilian Amazonia Between 1980 and 1995: Evidence from Integrated Satellite and Census Data, Remote Sens. Environ., 87, 551-562, 2003.

Chapin, F., Matson, P., and Mooney, H.: Principles of Terrestrial Ecosystem Ecology, Springer-Verlag, New York, 2002.
Chappell, N., Bidin, K., and Tych, W.: Modelling rainfall and canopy controls on net-precipitation beneath selectively-logged tropical forest, Plant Ecology, 153, 215-229, 2001.

Chave, J., Riera, B., and Dubois, M.: Estimation of biomass in a neotropical forest of French Guiana: spatial and temporal variability, J. Trop. Ecol., 17, 79-96, 2001.

Chave, J., Muller-Landau, H. C., Baker, T. R., Easdale, T. A., Ter Steege, H., and Webb, C. O.: Regional and phylogenetic variation of wood density across 2456 neotropical tree species, Ecol. Appl., 16, 2356-2367, 2006.

Chen, C. and Cotton, W.: A One-Dimensional Simulations of the Stratocumulus-Capped Mixed Layer, Bound.-Lay. Meteorol., 25, 289-321, 1983.

Collatz, G. J., Ball, J., Grivet, C., and Berry, J. A.: Physiological and environmental regulation of stomatal conductance, photosynthesis and transpiration: a model that includes a laminar boundary layer, Agr. Forest Meteorol., 54, 107-136, 1991.

Collatz, G. J., Ribas-Carbo, M., and Berry, J.: Coupled Photosynthesis-Stomatal Conductance Model for Leaves of $\mathrm{C}_{4}$ Plants, Aust. J. Plant Physiol., 19, 519-538, 1992.

Cotton, W., Pielke, R., Walko, R., Liston, G., Tremback, C., Jiang, H., McAnelly, R., Harrington, J., Nicholls, M., Carrio, G., and McFadden, J.: RAMS 2001: Current status and future directions, Meteorol. Atmos. Phys., 82, 5-29, 2003.

Crockford, R. and Richardson, D.: Partitioning of rainfall into throughfall, stemflow and interception: effect of forest type, ground cover and climate, Hydrol. Process., 14, 2903-2920, 2000.

d'Almeida, C., Vörösmarty, C. J., Hurtt, G. C., Marengo, J. A., Dingman, S. L., and Keim, B. D.: The effects of deforestation on the hydrological cycle in Amazonia: a review on scale and resolution, Int. J. Climatol., 27, 633-647, 2007.

Dalu, G. A., Pielke, R. A., Baldi, M., and Zeng, X.: Heat and momentum fluxes induced by thermal inhomogeneities, J. Atmos. Sci., 53, 3286-3302, 1996.

Dee, D. P., Uppala, S. M., Simmons, A. J., Berrisford, P., Poli, P., Kobayashi, S., Andrae, U., Balmaseda, M. A., Balsamo, G., Bauer, P., Bechtold, P., Beljaars, A. C. M., van de Berg, L., Bidlot, J., Bormann, N., Delsol, C., Dragani, R., Fuentes, M., Geer, A. J., Haimberger, L., Healy, S. B., Hersbach, H., Hólm, E. V., Isaksen, L., Kållberg, P., Köhler, M., Matricardi, M., McNally, A. P., Monge-Sanz, B. M., Morcrette, J.-J., Park, B.-K., Peubey, C., de Rosnay, P., Tavolato, C., Thépaut, J.-N., and Vitart, F.: The ERA-Interim reanlysis: configuration and performance of the data assimilation system, Q. J. Roy. Meteorol. Soc., 137, 553-597, 2011.

Dickinson, R. and Henderson-Sellers, A.: Modeling Tropical Deforestation: A Study of GCM Land-Surface Parameterization, Q. J. Roy. Meteorol. Soc., 114, 439-462, 1988.

Dietz, J., Hoelscher, D., Leuschner, C., and Hendrayanto: Rainfall partitioning in relation to forest structure in differently managed montane forest stands in Central Sulawesi, Indonesia, Forest Ecol. Manage., 237, 170-178, 2006.

Dietze, M., Wolosin, M., and Clark, J.: Capturing diversity and inerspecific variability in allometries: A hierarchical approach, Forest Ecol. Manage., 256, 1939-1948, 2008.

Eltahir, E.: Role of Vegetation in Sustaining Large-Scale Atmospheric Circulations in the Tropics, J. Geophys. Res.-Atmos., 101, 4255-4268, 1996. 
Eltahir, E. and Bras, R.: On the Response of the Tropical Atmosphere to Large-Scale Deforestation, Q. J. Roy. Meteorol. Soc., 119, 779-793, 1993.

Eltahir, E. A. B. and Bras, R.: Precipitation recyling in the Amazon basin, Q. J. Roy. Meteorol. Soc., 120, 861-880, 1994.

Fisch, G., Tota, J., Machado, L., Dias, M., Lyra, R., Nobre, C., Dolman, A., and Gash, J.: The convective boundary layer over pasture and forest in Amazonia, Theor. Appl. Climatol., 78, 47-59, 2004.

Freitas, S. R., Rodrigues, L. F., Longo, K. M., and Panetta, J.: Impact of a monotonic advection scheme with low numerical diffusion on transport modeling of emissions from biomass burning, J. Adv. Model. Earth Syst., 4, Q1, doi:10.1029/2011MS000084, 2012.

Gedney, N. and Valdes, P.: The effect of Amazonian deforestation on the northern hemisphere circulation and climate, Geophys. Res. Lett., 27, 3053-3056, 2000.

Geist, H. and Lambin, E.: Proximate Causes of Underlying Driving Forces of Tropical Deforestation, Bioscience, 52, 143-150, 2002.

Grell, G. A. and Dévényi, D.: A generalized approach to parameterizing convection combining ensemble and data assimilation techniques, Geophys. Res. Lett., 29, 38-1-38-4, 2002.

Harrington, J. and Olsson, P.: A Method for the Parameterization of Cloud Optical Properties in Bulk and Bin Microphysical Models. Implications for Arctic Cloud Boundary Layers, Atmos. Res., 57, 51-80, 2001.

Henderson-Sellers, A., Dickinson, R., Durbridge, T., Kennedy, P., McGufie, K., and Pitman, A.: Tropical Deforestation: Modeling Local to Regional Scale Climate Change, J. Geophys. Res., 98, 7289-7315, 1993.

Hurtt, G., Frolking, S., Fearon III, M. B. M., Shevialokova, E., Malyshew, S., Pacala, S., and Houghton, R.: The underpinnings of land-use history: three centuries of global gridded land-use transitions, wood harvest activity and resulting secondary lands, Global Change Biol., 12, 1-22, 2006.

INPE: Monitoring of the Amazon forest by satellite 2001-2002, Instituto Nacional de Pesquisas Espaciais, Technical Paper, Sao Jose Dos Campos, Brazil, 2003.

Jung, M., Reichstein, M., and Bondeau, A.: Towards global empirical upscaling of FLUXNET eddy covariance observations: validation of a model tree ensemble approach using a biosphere model, Biogeosciences, 6, 2001-2013, doi:10.5194/bg-6-20012009, 2009.

Jung, M., Reighstein, M., Margolis, H., Cescatti, A., Richardson, A., Arain, M. A., Arneth, A., Bernhofer, C., Bonal, D., Chen, J., Gianelle, D., Gobron, N., Kiely, G., Kutsch, W., Lasslop, G., Law, B., Lindroth, A., Merbold, L., Montagnani, L., Moors, E. J., Papale, D., Sottoconrola, M., Vaccari, F., and Williams, C.: Global Patterns of Land-Atmosphere Fluxes of Carbon Dioxide, Latent Heat, and Sensible Heat Derived from Eddy Covariance, Satellite and Meteorological Observations, J. Geophys. Res., 116, 1-16, 2011.

Kain, J.: The Kain-Fritsch Convective Parameterization: An Update, J. Appl. Meteorol., 43, 170-181, 2004.

Kain, J. and Fritsch, J.: A One-Dimensional Entraining-Detraining Plume Model and Its Application in Convective Parameterization, J. Atmos. Sci., 47, 2784-2802, 1990.
Kennard, D. and Gholz, H.: Effects of high- and low-intensity fires on soil properties and plant growth in a Bolivian dry forest, Plant Soil, 234, 119-129, 2001.

Kleidon, A. and Heimann, M.: Assessing the Role of Deep Rooted Vegetation in the Climate System with Model Simulations: Mechanism, Comparison to Observations and Implications for Amazonian Deforestation, Clim. Dynam., 16, 183-199, 2000.

Knox, R.: Land Conversion in Amazonia and Northern South America; Influences on Regional Hydrology and Ecosystem Response, $\mathrm{PhD}$ thesis, Massachusetts Institute of Technology, Cambridge, Massachusetts, USA, 2012.

Knox, R., Bisht, G., Wang, J., and Bras, R.: Precipitation Variability over the Forest-to-Nonforest Transition in Southwestern Amazonia, J. Climate, 24, 2368-2377, 2011.

Lal, R.: Deforestation and land-use effects on soil degradation and rehabilitation in western Nigeria, 1. Soil physical and hydrological properties, Land Degred. Develop., 7, 19-45, 1996.

Lammering, B. and Dwyer, I.: Improvement of Water Balance in Land Surface Schemes by Random Cascade Disaggregation of Rainfall, Int. J. Climatol., 20, 681-695, 2000.

Laurance, W., Cochrane, M., Bergen, S., Fearnside, P., Delamonica, P., Barber, C., D’Angelo, S., and Fernandes, T. The future of the Brazilian Amazon, Science, 291, 438-439, doi:10.1126/science.291.5503.4382001.

Laurance, W., Nascimento, H., Laurance, S., Condit, R., D’Angelo, S., and Andrade, A.: Inferred longevity of Amazonian rainforest trees based on a long-term demographic study, Forest Ecol. Manage., 190, 131-143, 2004.

Lean, J. and Warrilow, D.: Simulation of the Regional Climatic Impact of Amazon Deforestation, Nature, 342, 411-413, 1989.

Lee, T. and Pielke, R.: Estimating the Soil Surface SpecificHumidity, J. Appl. Meteorol., 31, 480-484, 1992.

Leuning, R.: A critical appraisal of a combined stomatalphotosynthesis model for C3 plants, Plant Cell Environ., 18, 339-355, 1995.

Lewis, S.: Tropical forests and the changing earth system, Philos. T. Roy. Soc. B, 361, 195-210, 2006.

Martinez, L. and Zinck, J.: Temporal variation of soil compaction and deterioration of soil quality in pasture areas of Colombian Amazonia, Soil Till. Res., 75, 3-17, 2004.

Massman, W.: An Analytical One-Dimensional Model of Momentum Transfer by Vegetation of Arbitrary Structure, Bound.-Lay. Meteorol., 83, 407-421, 1997.

Medvigy, D., Wofsy, S., Munger, J., Hollinger, D., and Moorcroft, P.: Mechanistic scaling of ecosystem function and dynamics in space and time: Ecosystem Demography model version 2, J. Geophys. Res., 114, 1-21, 2009.

Medvigy, D., Walko, R., Otte, M., and Avissar, R.: The OceanLand-Atmosphere-Model: Optimization and Evaluation of Simulated Radiative Fluxes and Precipitation, Mon. Weather Rev., 138, 1923-1939, 2010.

Medvigy, D., Walko, R., and Avissar, R.: Effects of Deforestation on Spatiotemporal Distributions of Precipitation in South America, J. Climate, 24, 2147-2163, 2011.

Moorcroft, P., Hurtt, G., and Pacala, S.: A Method for Scaling Vegetation Dynamics: The Ecosystem Demography Model, Ecol Monogr., 71, 557-586, 2001. 
Muñoz-Villers, L. E. and McDonnell, J. J.: Land use change effects on runoff generation in a humid tropical montane cloud forest region, Hydrol. Earth Syst. Sci., 17, 3543-3560, doi:10.5194/hess17-3543-2013, 2013.

Nakanishi, M. and Niino, H.: An improved Mellor-Yamada level-3 model with condensation physics: its numerical stability and application to a regional prediction of advection fog, Bound.-Lay. Meteorol., 119, 397-407, 2006.

Nepstad, D., de Carvalho, C., Davidson, E., Jipp, P., Lefebvre, P., Negreiros, H., dal Silva, E., Stone, T., Trubore, S., and Vieira, S.: The Role of Deep Roots in the Hydrological and Carbon Cycles of Amazonian Forests and Pastures, Nature, 372, 666-669, 1994.

Nepstad, D., Carvalho, G., Barros, A., Alencar, A., Capobianco, J., amd P. Moutinho, J. B., Lefebvre, P., Silva, U. L., and Prins, E.: Road paving, Fire Regime Feedbacks and the Future of Amazon Forests, Forest Ecol. Manage., 154, 395-407, 2001.

Nobre, C., Sellers, P., and Shukla, J.: Amazonian Deforestation and Regional Climate Change, J. Climate, 4, 957-988, 1991.

Pielke, R.: Influence of the spatial distribution of vegetation and soils on the prediction of cumulus convective rainfall, Rev. Geophys., 39, 151-171, 2001.

Pitman, A., Henderson-Sellers, A., and Yang, Z.: Sensitivity of Regional Climates to Localized Precipitation in Global-Models, Nature, 346, 734-737, 1990.

Poorter, L., Bongers, L., and Bongers, F.: Architecture of 54 moistforest tree species: traits, trade-offs and functional groups, Ecology, 87, 1289-1301, 2006.

Quesada, C. A., Lloyd, J., Anderson, L. O., Fyllas, N. M., Schwarz, M., and Czimczik, C. I.: Soils of Amazonia with particular reference to the RAINFOR sites, Biogeosciences, 8, 1415-1440, doi:10.5194/bg-8-1415-2011, 2011.

Raupach, M., Finnigan, J., and Brunet, Y.: Coherent eddies and turbulence in vegetation canopies: The mixing-layer analogy, Bound.-Lay. Meteorol., 78, 351-382, 1996.

Rossato, L.: Estimativa da capacidade de armazenamento de água no solo do Brasil, Msc. thesis, Instituto Nacional de Pesquisas Espaciais (INPE), São José dos Campos, Brazil, 2001.

Scholes, R., Skole, D., and (eds.), J. I.: A Global Database of Soil Properties: Proposal for Implementation, Report of the Global Soils Task Group, Tech. Rep. IGBP-DIS Working Paper 10a, International Geosphere-Biosphere Programme - Data and Information System (IGBP-DIS), University of Paris, Paris, France, 1995.

Sheffield, J., Goteti, G., and Wood, E.: Development of a 50-Year High-Resolution Global Dataset of Meteorological Forcings for Land Surface Modeling, J. Climate, 19, 3088-3111, 2006.

Silva, R. R. D., Werth, D., and Avissar, R.: Regional impacts of future land-cover changes on the Amazon basin wet-season climate, J. Climate, 21, 1153-1170, 2008.

Skole, D. and Tucker, C.: Tropical Deforestation and Habitat Fragmentation in the Amazon: Satellite Data from 1978 to 1988, Science, 260, 1905-1910, 1993.
Snyder, P. K.: The Influence of Tropical Deforestation on the Northern Hemisphere Climate by Atmospheric Teleconnections, Earth Interact., 14, 1-34, doi:10.1175/2010EI280.1, 2010.

Soares-Filho, B. S., Nepstad, D. C., Curran, L. M., Cerqueira, G. C., Garcia, R. A., Ramos, C. A., Voll, E., McDonald, A., Lefebvre, P., and Schlesinger, P.: Modelling conservation in the Amazon basin, Nature, 440, 520-523, 2006.

Souza, E. P., Renno, N. O., and Silva-Dias, M. A. F.: Convective circulations induced by surface heterogeneities, J. Atmos. Sci., 57, 2915-2922, 2000.

Tremback, C. and Kessler, R.: A surface temperature and moisture parameterization for use in mesoscale models, Preprints, Seventh Conf. on Numerical Weather Prediction, Montreal, PQ, Canada, Amer. Meteor. Soc., 355-358, 1985.

Walcek, C. and Aleksic, N.: A simple but accurate mass conservative, peak-preserving, mixing ratio bounded advection algorithm with Fortran code, Atmos. Environ., 32, 3863-3880, 1998.

Walker, R., Moore, N., Arima, E., Perz, S., Simmons, C., Caldas, M., Vergara, D., and Bohrer, C.: Protecting the Amazon with protected areas, P. Natl. Acad. Sci. USA, 106, 10582-10586, 2009.

Walko, R., Band, L., Baron, J., Kittel, T., Lammers, R., Lee, T., Ojima, D., Pielke, R., Taylor, C., Tague, C., Tremback, C., and Vidale, P.: Coupled atmosphere-biophysics-hydrology models for environmental modeling, J. Appl. Meteorol., 39, 931-944, 2000.

Wang, D., Wang, G., and Anagnostou, E. N.: Evaluation of canopy interception schemes in band surface models, J. Hydrol., 347, 308-318, 2007.

Wang, J., Bras, R., and Eltahir, E.: The Impact of Observed Deforestation on the Mesoscale Distribution of Rainfall and Clouds in Amazonia, J. Hydrometeorol., 1, 267-286, 2000.

Wang, J., Chagnon, F., Williams, E., Betts, A., Renno, N., Machado, L., Bisht, G., Knox, R., and Bras, R.: The impact of deforestation in the Amazon basin on cloud climatology, P. Natl. Acad. Sci., 106, 3670-3674, 2009.

Williams, E. and Renno, N.: An Analysis of the Conditional Stability of the Tropical Atmosphere, Mon. Weather Rev., 121, 21-36, 1993.

Zhao, W. and Qualls, R. J.: A multiple-layer canopy scattering model to simulate shortwave radiation distribution within a homogeneous plant canopy, Water Resour. Res., 41, W08409, doi:10.1029/2005WR004016, 2005.

Zhao, W. and Qualls, R. J.: Modeling of long-wave and net radiation energy distribution within a homogeneous plant canopy via multiple scattering processes, Water Resour. Res., 42, W08436, doi:10.1029/2005WR004581, 2006.

Zimmermann, B., Elsenbeer, H., and De Moraes, J.: The influence of land-use changes on soil hydraulic properties: Implications for runoff generation, Forest Ecol. Manage., 222, 29-38, 2006. 